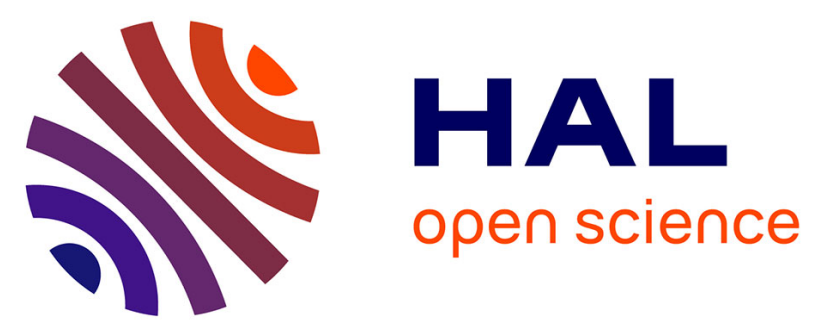

\title{
Clay Swelling in Dry Supercritical Carbon Dioxide: Effects of Interlayer Cations on the Structure, Dynamics, and Energetics of CO2 Intercalation Probed by XRD, NMR and GCMD Simulations
}

Narasimhan Loganathan, Geoffrey M. Bowers, A. Ozgur Yazaydin, Herbert

Todd Schaef, John Loring, Andrey G. Kalinichev, R. James Kirkpatrick

\section{To cite this version:}

Narasimhan Loganathan, Geoffrey M. Bowers, A. Ozgur Yazaydin, Herbert Todd Schaef, John Loring, et al.. Clay Swelling in Dry Supercritical Carbon Dioxide: Effects of Interlayer Cations on the Structure, Dynamics, and Energetics of CO2 Intercalation Probed by XRD, NMR and GCMD Simulations. Journal of Physical Chemistry C, 2018, 122 (8), pp.4391 - 4402. 10.1021/acs.jpcc.7b12270 . in2p3-01891525

HAL Id: in2p3-01891525

https://hal.in2p3.fr/in2p3-01891525

Submitted on 9 Oct 2018

HAL is a multi-disciplinary open access archive for the deposit and dissemination of scientific research documents, whether they are published or not. The documents may come from teaching and research institutions in France or abroad, or from public or private research centers.
L'archive ouverte pluridisciplinaire HAL, est destinée au dépôt et à la diffusion de documents scientifiques de niveau recherche, publiés ou non, émanant des établissements d'enseignement et de recherche français ou étrangers, des laboratoires publics ou privés. 
Clay Swelling in Dry Supercritical Carbon Dioxide: Effects of Interlayer Cations on the Structure, Dynamics, and Energetics of $\mathrm{CO}_{2}$ Intercalation Probed by XRD, NMR and GCMD Simulations

Narasimhan Loganathan ${ }^{1},{ }^{*}$ Geoffrey M. Bowers ${ }^{2}$, A. Ozgur Yazaydin ${ }^{1,3}$ H. Todd Schaef ${ }^{4}$, John S. Loring ${ }^{4}$, Andrey G. Kalinichev ${ }^{5}$ and R. James Kirkpatrick ${ }^{6}$

${ }^{1}$ Department of Chemistry, Michigan State University, East Lansing, Michigan 48824, United States

${ }^{2}$ Department of Chemistry and Biochemistry, St. Mary’s College of Maryland, St. Mary’s City, Maryland 20686, United States

${ }^{3}$ Department of Chemical Engineering, University College London, London, WC1E7JE, United Kingdom

${ }^{4}$ Pacific Northwest National Laboratory, Richland, WA, 99352, United States

${ }^{5}$ Laboratoire SUBATECH (UMR 6457 - Institut Mines-Télécom Atlantique, Université de Nantes, CNRS/IN2P3), 44307, Nantes, France

${ }^{6}$ College of Natural Science, Michigan State University, East Lansing, Michigan 48824, United States

*Corresponding author e-mail: naresh20@msu.edu 


\section{Abstract}

In situ XRD and NMR experiments combined with molecular dynamics simulations using the grand canonical ensemble (GCMD) show that cation size, charge and solvation energy play critical roles in determining the interlayer expansion of smectite clay minerals when exposed to dry supercritical $\mathrm{CO}_{2}$ under conditions relevant to the earth's upper crust, petroleum reservoirs, and geological $\mathrm{CO}_{2}$ sequestration conditions (323 $\mathrm{K}$ and 90 bar). The GCMD results show that the smectite mineral, hectorite, containing interlayer alkali and alkaline earth cations with relatively small ionic radii and high solvation energies (e.g., $\mathrm{Li}^{+}$, $\mathrm{Na}^{+} \mathrm{Mg}^{2+}$, and $\mathrm{Ca}^{2+}$ ) does not intercalate dry $\mathrm{CO}_{2}$ and that the fully collapsed interlayer structure is the energetically most stable configuration. With increasing cation size and decreasing cation solvation energy, the energy barrier to $\mathrm{CO}_{2}$ intercalation decreases. With $\mathrm{K}^{+}$, $\mathrm{Rb}^{+}, \mathrm{Cs}^{+}, \mathrm{Sr}^{2+}$, and $\mathrm{Ba}^{2+}$ the monolayer structure is the stable configuration, and $\mathrm{CO}_{2}$ should spontaneously enter the interlayer. With $\mathrm{Cs}^{+}$there is not even an energy barrier for $\mathrm{CO}_{2}$ intercalation, in agreement with the experimental XRD and NMR results that show clay layer expansion and $\mathrm{CO}_{2}$ incorporation. The number of intercalated $\mathrm{CO}_{2}$ molecules decreases with increasing size of the alkali cation but does not vary with ion size for the alkaline earth cations. ${ }^{13} \mathrm{C}$ NMR spectroscopy and the GCMD simulations show that the average orientation of the intercalated $\mathrm{CO}_{2}$ molecules is with their O-C-O axes parallel to the basal clay surface and that they undergo a combination of rapid rotation about an axis perpendicular to the main molecular axis and wobbling motion with respect to the basal surface. Incorporation of $\mathrm{CO}_{2}$ in the interlayer decreases the coordination of $\mathrm{Cs}^{+}$by the oxygen atoms of the basal surfaces, which is compensated by $\mathrm{CO}_{2}$ molecules entering their solvation shell, as predicted based on previously published NMR results. The GCMD simulations show that the strength of the interaction between the exchangeable cation and the clay structure dominates the intercalation energetics in dry $\mathrm{scCO}_{2}$. With relatively small cations, the cation-clay interactions outcompete cation solvation by $\mathrm{CO}_{2}$ molecules. The computed residence times for coordination among of interlayer species are consistent with the computed energetics. 


\section{Introduction}

Injection of $\mathrm{CO}_{2}$ into deep geological formations and depleted oil and gas reservoirs is an effective method for enhancing oil recovery and a potential pathway for reducing anthropogenic $\mathrm{CO}_{2}$ in the atmosphere. Target geological storage sites are primarily composed of porous rock formations in which the $\mathrm{CO}_{2}$ is confined by overlying caprocks that act as low permeability barriers to upward fluid flow. ${ }^{1-8}$ Long-term confinement of $\mathrm{CO}_{2}$ depends strongly on its interactions with these caprocks, which are typically shales containing significant amounts of clay minerals. Intercalation and nano-confinement of fluids in the 2-dimensional interlayer galleries of expandable clays (principally smectites and smectite layers in mixed layer illite-smectites) may affect the properties and porosity of the caprocks by expanding or shrinking the interlayer pores (tracked via the basal spacings) ${ }^{9-24}$ and can lead to substantial changes in the structural and dynamical behavior of the intercalated fluid molecules with respect to the bulk fluid phase. Numerous studies ${ }^{25-39}$ provide critical molecular-scale information about the role of the clay composition, location of its structural charge, and the properties of the charge compensating cation in determining the structure, dynamics, energetics and reactivity of $\mathrm{H}_{2} \mathrm{O}$ in the interlayer galleries and inter-particle pore space.

Recent experimental and molecular simulation studies at conditions relevant to subsurface injection of supercritical $\mathrm{CO}_{2}{ }^{9-23,40-48}$ have shown that the intercalation and retention of $\mathrm{CO}_{2}$ in smectite interlayers is possible but depends strongly on the amount and thermodynamic properties of water in the system. For example, Giesting et al. ${ }^{11,12}$ and Schaef et al. ${ }^{17,19}$ have shown that the $\mathrm{H}_{2} \mathrm{O}$ saturation state (relative humidity, R.H.) of supercritical $\mathrm{CO}_{2}\left(\mathrm{scCO}_{2}\right)$ controls $\mathrm{CO}_{2}$ intercalation in Na-, Mg- and Ca-montmorillonite at $323 \mathrm{~K}$ and 90 bar. The results show that no $\mathrm{CO}_{2}$ enters the dry and collapsed interlayers of these smectites and that $\mathrm{CO}_{2}$ intercalation only occurs in the presence of at least a sub-monolayer of $\mathrm{H}_{2} \mathrm{O}$. This humidity-dependent intercalation was further validated by Loring et al., ${ }^{20-22}$ who also showed 
that the maximum $\mathrm{CO}_{2}$ intercalation at 90 bar and $323 \mathrm{~K}$ occurs when the interlayer $\mathrm{H}_{2} \mathrm{O}$ content is equivalent to that of a monolayer hydrate structure. In situ experimental NMR, IR, and XRD of the similar smectite mineral, hectorite, at 90 bar $\mathrm{CO}_{2}$ and $323 \mathrm{~K}$ by Bowers et al. ${ }^{9}$ showed that the properties of the charge balancing cation can greatly change the $\mathrm{CO}_{2}$ intercalation behavior. These results show that for the cations with relatively high hydration energies and small ionic radii $\left(\mathrm{Na}^{+}, \mathrm{Ca}^{2+}\right), \mathrm{CO}_{2}$ intercalation requires the presence of $\mathrm{H}_{2} \mathrm{O}$ molecules to prop open the interlayers. In contrast, $\mathrm{Cs}^{+}$with a larger ionic radius and smaller hydration energy allows Cs-hectorite to intercalate $\mathrm{CO}_{2}$ readily even in the complete absence of water $\left(\mathrm{R} . \mathrm{H}\right.$. of the $\left.\mathrm{scCO}_{2}=0\right)$. With all three cations, increasing $\mathrm{H}_{2} \mathrm{O}$ saturation of the $\mathrm{scCO}_{2}$ rich fluid phase causes a decreasing interlayer molar $\mathrm{CO}_{2} /\left(\mathrm{CO}_{2}+\mathrm{H}_{2} \mathrm{O}\right)$ ratio, with Cs-hectorite maintaining a higher ratio at all conditions. Computational molecular simulations of nanoconfined $\mathrm{CO}_{2}-\mathrm{H}_{2} \mathrm{O}$ mixtures in smectites in equilibrium with water-saturated $\mathrm{CO}_{2}$ at $348 \mathrm{~K}$ and 125 bar using the grand canonical Monte Carlo (GCMC) ensemble by Botan et al. ${ }^{40}$ have suggested that the stable state of Na-montmorillonite exposed to supercritical $\mathrm{CO}_{2}$ is the bilayer hydrate (basal spacing $~ 15.0 \AA$ ) but that maximum $\mathrm{CO}_{2}$ intercalation occurs at the monolayer hydrate state. Recently GCMC simulations by Kadoura et al. ${ }^{41}$ show that for montmorillonite at high R.H.s ( $\geq 60 \%$ ) at $323 \mathrm{~K}$ and 90 bar there is no significant difference in the interlayer $\mathrm{CO}_{2}$ content with cations having different hydration energies $\left(\mathrm{Na}^{+}, \mathrm{Ca}^{2+}, \mathrm{Mg}^{2+}\right)$. Simulation studies using GCMC and Gibbs ensemble Monte Carlo (GEMC) have indicated that for Nasmectite under similar conditions $\mathrm{CO}_{2}$ intercalation can vary depending on the clay layer charge and its structural location. ${ }^{42-45}$ Recently, we reported grand canonical molecular dynamics (GCMD) simulations that show that varying temperature (323-368 K) and pressure (90150 bar) have little impact on the structural environments and dynamics of intercalated $\mathrm{CO}_{2}$ molecules in Na-hectorite in equilibrium with $\mathrm{H}_{2} \mathrm{O}$-saturated $\mathrm{scCO}_{2}{ }^{48}$ 
Intercalation of dry $\mathrm{CO}_{2}$ in smectite interlayers has been less extensively studied but is important as a limiting energetic and structural case and may have significant application to situations when dry $\mathrm{CO}_{2}$ is injected into the subsurface. Mineralogical studies using X-ray computed tomography before and after $\mathrm{CO}_{2}$ injection have suggested that $\mathrm{scCO}_{2}$ can laterally displace the brine in that occupies the pore volumes of the host sedimentary rocks causing either anhydrous or nearly anhydrous conditions, especially during the early stages of injection. ${ }^{1,6,49,50}$ Under these circumstances, the dry $\mathrm{CO}_{2}$ could potentially enter and dehydrate the smectite interlayers, cause swelling or shrinking of the clay, and thus generate mechanical stresses and alter the overall pore structure of shale caprocks. It could also suppress hydration reactions involving the mineral phases due to a lack of residual $\mathrm{H}_{2} \mathrm{O}$ in the pore fluid. Our previous experimental studies have shown that collapsed Na-montmorillonite does not intercalate $\mathrm{CO}_{2}$ or expand when exposed to dry $\mathrm{CO}_{2}$ under reservoir conditions (323 $\mathrm{K}$ and 90 bar), whereas Cs- and $\mathrm{NH}_{4}$-montmorillonite do. ${ }^{51}$ Parallel GCMD calculations are consistent with these results, showing a large energy barrier for $\mathrm{CO}_{2}$ intercalation in $\mathrm{Na}$ montmorillonite but no such barrier Cs- and $\mathrm{NH}_{4}$-montmorillonites. ${ }^{51}$ These results suggest that the exchangeable cation has a significant effect on the intercalation behavior under dry $\mathrm{CO}_{2}$ conditions, although the energetic origin of these effects and the associated structural and dynamical behavior have not been explored in detail.

In the present work, we combine in situ experimental nuclear magnetic resonance spectroscopy (NMR) and X-ray diffraction (XRD) studies at a $\mathrm{CO}_{2}$ pressure of 90 bar and a temperature of $323 \mathrm{~K}$ with GCMD calculations to investigate the structure, dynamics and energetics of the intercalation of dry $\mathrm{CO}_{2}$ in the smectite mineral, hectorite, containing monovalent and divalent cations spanning a range of hydration and solvation properties. We used hectorite as our host material for the experiments and modeling studies, because it has a very low Fe content that improves NMR spectral resolution by minimizing paramagnetic 
effects affecting most natural montmorillonites. Like montmorillonite, hectorite develops most of its permanent structural charge by cation substitution in the octahedral layer, and it has been used for many NMR studies to examine smectite behavior. 9,24,26,28,29,31,52

\section{Experimental Methods}

\section{In Situ XRD}

Na- and Cs-exchanged hectorite samples were characterized by XRD at $323 \mathrm{~K}$ first under vacuum ( $10^{-3}$ Torr) and then during exposure to dry $\mathrm{CO}_{2}$ at a pressure of 90 bar using high pressure and temperature X-ray diffraction techniques previously described. ${ }^{9,17,19,51}$ The Cs-hectorite was also reexamined under vacuum conditions at $323 \mathrm{~K}$ after the $\mathrm{CO}_{2}$ was removed. The base hectorite was SHCa-1, which is available at the Clay Source Repository of the Clay Minerals Society.

Hectorite is a 2:1 trioctahedral smectite clay mineral that develops negative structural charge due to $\mathrm{Li}^{+}$for $\mathrm{Mg}^{2+}$ substitution in the octahedral layer. The structural formula of this sample, that was processed to remove carbonate and quartz impurities, is $\left[\mathrm{M}_{0.36}\left(\mathrm{Mg}_{2.65} \mathrm{Li}_{0.35}\right)\left(\mathrm{Si}_{3.99} \mathrm{Al}_{0.01}\right) \mathrm{O}_{10}\left(\mathrm{~F}_{1.1} \mathrm{OH}_{0.9}\right)\right] .{ }^{28,29}$ For these experiments, measured aliquots of dilute clay suspensions in water were pipetted onto a beryllium post, with each sample occupying a circular area with an approximate diameter of 2-3 mm. Each clay sample was allowed to air dry to produce a thin preferentially oriented film. The beryllium post was then placed on an $X Y Z$ stage and the samples were aligned with the aid of a laser system, allowing exposure of only one clay film at a time to the XRD beam. Once the sample coordinates were established, the pressurized reactor was assembled, mounted into the instrument, and heated to $323 \mathrm{~K}$. Subsequent exposure to vacuum for 30 minutes removed most of the water from the clay samples. Pressurization with $\mathrm{CO}_{2}$ was accomplished through an ISCO pump connected directly to the reactor. 
XRD patterns were collected using a Bruker D8 Discover instrument with a rotating $\mathrm{Cu}$ anode (CuK alpha $=1.5418 \AA$ ), a programmable $X Y Z$ customized stage, and a Vantec 500 detector set at a sample-to-detector distance of $15 \mathrm{~cm}$. This instrument, operated at $50 \mathrm{kV}$ and $24 \mathrm{~mA}$, is capable of producing an intensely focused $0.5 \mathrm{~mm}$ beam. XRD patterns for each sample were acquired for 300 seconds, integrated over a $2 \vartheta$ range of $4-45^{\circ}$, and subsequently analyzed with the MDI JADE ${ }^{\circledR}$ XRD software package to obtain peak positions and peak profiles.

In Situ MAS NMR

In situ ${ }^{13} \mathrm{C}$ MAS NMR spectra were obtained at $323 \mathrm{~K}$ and 90 bars $P_{\mathrm{CO} 2}$ for the same Na- and Cs-exchanged hectorite samples examined by XRD using the high pressure apparatus that has been described previously. ${ }^{9,24}$ For these experiments, clay filled rotors were dried overnight in a vacuum oven at $323 \mathrm{~K}$ and $10^{-3}$ Torr. The rotors were sealed after backfilling the vacuum oven with dry $\mathrm{N}_{2}$ gas. Hectorite samples prepared in a similar way and analyzed by IR spectroscopy show no detectable $\mathrm{H}_{2} \mathrm{O}$ content with $\mathrm{Cs}^{+}$and $\leq 0.5 \mathrm{H}_{2} \mathrm{O}$ per cation with $\mathrm{Na}^{+}$. 99\% isotopically enriched ${ }^{13} \mathrm{CO}_{2}$ was then introduced into the rotor using a one-way flow system. ${ }^{53,54}$ The spectra were collected using a 7.0 T Varian DDR 2 console with a 5 mm HXY probe at a spin frequency of $3 \mathrm{kHz}$ using a $\pi / 2$ pulse width of $5 \mu$ s, a spectral width of $50 \mathrm{kHz}$, and a $30 \mathrm{~s}$ inter-pulse delay to obtain 3000 transients. The ${ }^{13} \mathrm{C}$ spectra were referenced to tetramethylsilane (TMS) through a secondary standard of adamantane using the high-frequency peak. All NMR data were processed using iNMR, a commercial program by MestReC, and all NMR results were iteratively fit using Abscissa, a freeware app written by Rudiger Bruhl. For ${ }^{13} \mathrm{C}$, the first two data points were removed due to acoustic ringing before zero filling to $32 \mathrm{k}$ points and applying $20 \mathrm{~Hz}$ of exponential apodization. In almost all cases a standard baseline correction was performed to flatten the baseline. All peak fits were performed by iteratively fitting the data set to Lorentzian lineshapes. 


\section{Simulation Methods}

The model hectorite used in our simulations has a structural formula of $\mathrm{M}^{+}\left(\mathrm{Mg}_{5} \mathrm{Li}\right) \mathrm{Si}_{8} \mathrm{O}_{20}(\mathrm{OH})_{4}$. This model has no tetrahedral substitutions, in accordance with the experimental sample, which contains a negligible fraction $(0.25 \%)$ of tetrahedral $\mathrm{Al}^{3+}$ for $\mathrm{Si}^{4+}$ substitution. ${ }^{9,26,28,29,31}$ The simulation model, however, differs from the experimental sample in two important respects. First, the model has a 30\% higher layer charge. Second, the $\mathrm{OH}^{-}$site in the model contains only $\mathrm{OH}^{-}$groups, whereas the experimental sample has $55 \% \mathrm{~F}^{-}$for $\mathrm{OH}^{-}$ substitution. The hydration behavior of synthetic fluoro-hectorite has been discussed previously. ${ }^{27,55,56}$ Previous simulation studies employing this model have shown good agreement with experimental data justifying its use here. ${ }^{30,33,35,47,48}$

The simulation supercell consists of 16 crystallographic unit cells of hectorite $(4 \times 2 \times$ 2) encompassing two interlayer galleries with surface areas of $360.23 \AA^{2}$. This supercell size is sufficient to eliminate any finite size effects. Isomorphic substitutions of $\mathrm{Li}^{+} / \mathrm{Mg}^{2+}$ in the supercell were performed in a quasi-disordered pattern following Lowenstein's rule to prevent $\mathrm{Li}^{+}-\mathrm{O}-\mathrm{Li}^{+}$next nearest neighbor arrangements. ${ }^{57}$ The structural details of the model are described elsewhere. ${ }^{30,33,35,48}$ Overall charge balance for the model is obtained by cation substitution in the interlayer galleries. Nine different compositions were simulated, each with the interlayer occupied by a single type of alkali or alkaline earth cation $\left(\mathrm{Li}^{+}, \mathrm{Na}^{+}, \mathrm{K}^{+}, \mathrm{Rb}^{+}\right.$, $\mathrm{Cs}^{+}, \mathrm{Mg}^{2+}, \mathrm{Ca}^{2+}, \mathrm{Sr}^{2+}$, or $\left.\mathrm{Ba}^{2+}\right)$.

Molecular dynamics simulations were performed in the grand canonical ensemble using the RASPA software package. ${ }^{58,59}$ Basal spacings were varied from $9.0 \AA$ to $18.0 \AA$ at steps of $0.2 \AA$ and were constrained at the initial value throughout each simulation run. All of the charge compensating cations were initially placed randomly in the interlayer region and were allowed to move during the GCMD runs. Importantly, during the simulations we permit lateral movements of the T-O-T layers parallel to each other (in the $x$ and $y$ directions) without 
disrupting the structure. These translational movements are essential, because the minimum energy interlayer structure depends on the relative positions of the adjacent T-O-T layers and varies with the type of the interlayer cation and the number of intercalated fluid molecules, as reported in previous studies. ${ }^{40,48,51,60}$

All the GCMD simulations were performed as described in our previous study of $\mathrm{H}_{2} \mathrm{O}$ and $\mathrm{CO}_{2}$ exchange in Na-hectorite. ${ }^{48}$ The GCMD approach is a hybrid technique which incorporates both Monte Carlo and molecular dynamics procedures by sampling the insertion and deletion of fluid molecules with equal probability at every MD time step. Therefore, temperature, volume and the chemical potential $(\mu)$ of the fluid molecules are fixed in our simulations, but the number of fluid molecules absorbed in the interlayer can fluctuate. The interatomic interactions for the T-O-T clay structure and the metal cations were described using the ClayFF force field, ${ }^{61}$ which is widely used in clay interfacial simulations. The $\mathrm{CO}_{2}$ molecules were represented using the rigid EPM2 model. ${ }^{62}$ Three-dimensional periodic boundary conditions were employed with a cutoff of $9.0 \AA$ for short range non-electrostatic interactions, and the long-range electrostatic interactions were computed using Ewald summation ${ }^{63}$ with an accuracy of $10^{-6}$. Fugacities are required to determine the acceptance of insertion and deletion moves for the fluid species (here $\mathrm{CO}_{2}$ ) and were calculated using the Peng-Robinson equation of state. ${ }^{64}$

All simulations were performed at $T=323 \mathrm{~K}$ and $P=90$ bar (the experimental conditions described above) for $15 \mathrm{~ns}$ to reach equilibrium followed by another $10 \mathrm{~ns}$ of data production with a time step of $1 \mathrm{fs}$. The reported adsorption profile and related energetics, interlayer structure and dynamics were calculated using the data from the last 5 ns of each equilibrium simulation run. The methods of analysis can be found in our previous papers. ${ }^{33,35,48,65}$ The computed energetics of each system is evaluated using the immersion energies, which were computed by considering the largest basal spacings (18.0 $\AA$ ) as the reference state because its 
value is the closest to that of bulk $\mathrm{CO}_{2}$ than any other basal spacing. The use of immersion energies to investigate the equilibrium states of smectites have been discussed previously mostly for water adsorption $33,35,37,48,51,65$ and is extended here to $\mathrm{CO}_{2}$.

\section{Results and Discussion}

$X R D$

The in situ XRD results (Figure 1$)$ show that the basal spacing ( $d_{001}$ basal reflection) of Cs-hectorite increases reversibly by about $1 \AA$ on exposure to dry $\mathrm{CO}_{2}$, but that the basal spacing of Na-hectorite does not change. We interpret these results to indicate that under our experimental conditions, $\mathrm{CO}_{2}$ readily enters the interlayer galleries of Cs-hectorite but not $\mathrm{Na}$ hectorite. The specific basal spacings of the Cs-hectorite before and after exposure to dry $\mathrm{CO}_{2}$ (11.06 $\AA$ and $12.05 \AA$, respectively) are the same as previously reported. ${ }^{9}$ They are also consistent with values reported in the literature for similar samples and conditions. ${ }^{33,37,51,57,65,66}$ After a few minutes of exposure to vacuum conditions following equilibration with dry $\mathrm{scCO}_{2}$, the basal spacing of Cs-hectorite returns to its original value, suggesting that there is not a significant quantity of recalcitrant $\mathrm{CO}_{2}$ in the interlayers. ${ }^{9}$ For Na-hectorite, previous in situ IR data for this sample ${ }^{9}$ show nearly complete removal of interlayer water and a lack of expansion when exposed to dry $\mathrm{scCO}_{2}$. Fully dehydrated Na-SHCa-1 sample has a basal spacing of $9.7 \AA,{ }^{26}$ and the value of $9.81 \AA$ observed here indicates removal of all or most of the interlayer water. In addition, XRD did not detect formation of a carbonate phase in either the Cs- or Nahectorite.

${ }^{13}$ C MAS NMR

As for the XRD results, the ${ }^{13} \mathrm{C}$ MAS NMR results indicate sorption of $\mathrm{CO}_{2}$ in the interlayers of Cs-hectorite but not Na-hectorite. As discussed by Bowers, et al., ${ }^{9}$ the spectrum of $\mathrm{CO}_{2}$ in an empty rotor and with Na-SHCa-1 are very similar (Figure 2). Both contain a center band at $\sim 124 \mathrm{ppm}$ with a full width at half height (FWHH) of $\sim 0.11 \mathrm{ppm}$ that represents $\mathrm{CO}_{2}$ molecules that are undergoing rapid, isotropic tumbling in the supercritical fluid phase and that 
experience little interaction with the clay surface. ${ }^{9}$ Both these samples also show a pair of small spinning sidebands (SSBs). For the $\mathrm{scCO}_{2}$ without clay present, these SSBs must be associated with $\mathrm{CO}_{2}$ either adsorbed on the rotor wall or being compressed and densified against the wall due to the centrifugal forces caused by the rotor rotation. For the Na-SHCa-1 sample, the SSBs are likely to arise from similar effects, possibly including weak adsorption on or compressed against the exterior surfaces of the clay particles. ${ }^{9}$ Note that the spectrum for the Na-SHCa-1 sample in Figure 2 is greatly expanded vertically to show the SSBs. In contrast, for the Cshectorite, the center band is much broader, with a FWHH of $0.67 \mathrm{ppm}$, and there is a broader, asymmetric spinning sideband manifold. The sideband manifold for this sample is very similar to that reported previously for Cs-hectorite dried over $\mathrm{P}_{2} \mathrm{O}_{5}$ or equilibrated at $43 \%$ R.H. before exposure to dry $s c \mathrm{CO}_{2}{ }^{9}{ }^{9}$ It indicates a residual chemical shift anisotropy (CSA) associated with adsorption of $\mathrm{CO}_{2}$ molecules in an environment where they undergo anisotropic rotation. We previously assigned this pattern to adsorbed $\mathrm{CO}_{2}$ molecules in a monolayer hydrate-type $(\sim 12.5 \AA)$ interlayer arrangement with their long $(\mathrm{O}=\mathrm{C}=\mathrm{O})$ molecular axes having a timeaveraged orientation parallel to the basal clay surface and experiencing rapid $\left(>10^{5} \mathrm{~Hz}\right)$ reorientation about an axis normal to the clay basal surface. ${ }^{9}$

The ${ }^{13} \mathrm{C}$ MAS NMR spectra for Cs-hectorite here are also similar to those published previously for Cs-exchanged Wyoming montmorillonite (Cs-SWy-2) with dry $\mathrm{CO}_{2}$ at 90 bar and $323 \mathrm{~K} .{ }^{51}$ Most importantly, both show similar SSB patterns indicating $\mathrm{CO}_{2}$ intercalation into the interlayer galleries where confinement induces restricted molecular reorientation. For the Cs-hectorite, however, the sidebands have on average a FWHH of 2.92 ppm, compared to $1.37 \mathrm{ppm}$ for the Cs-montmorillonite. The FWHH of the center band for the Cs-hectorite is also about twice that of the center band of the Cs-montmorillonite. This difference is surprising, because SWy-2 contains substantially more structural Fe than SHCa-1, ${ }^{9,29,31,51}$ and we expected that its ${ }^{13} \mathrm{C}$ NMR spectrum would show significant paramagnetic broadening as a 
result. Thus, it appears that in Cs-montmorillonite the motion of the $\mathrm{CO}_{2}$ molecules is effectively decoupling the ${ }^{13} \mathrm{C}$ and electron spin systems. The origin of the differences in peak widths for the Cs-hectorite and montmorillonite are uncertain at this time, but may be due to dynamical disorder, small differences in the interlayer $z$ dimension, or differences in the NMR powder averaging behavior related to the mean particle size, crystallite size, and packing density/geometry in the rotors. The spectrum for Cs-hectorite was obtained with a $5 \mathrm{~mm}$ rotor, whereas that for the Cs-montmorillonite was obtained with a $7.5 \mathrm{~mm}$ rotor, and the Cs-hectorite samples are ground and sieved to provide a controlled particle size in the rotors. In general, the $s c \mathrm{CO}_{2}$ fluid pockets in the center of the rotor cavity are larger with $7.5 \mathrm{~mm}$ than with $5 \mathrm{~mm}$ rotors, which may influence the exchange of $\mathrm{CO}_{2}$ between interlayer and bulk fluid environments.

\section{Computational Results}

Adsorption Profile and Energetics

The computational modeling results show that the properties of the exchangeable cations have significant effects on the structural and energetic behavior of smectite- $\mathrm{CO}_{2}$ systems and are in good agreement with the experimental results discussed above. For all the simulated systems, $\mathrm{CO}_{2}$ intercalation begins at a basal spacing of $\sim 11.0 \AA$ except with $\mathrm{Mg}^{2+}$, for which it begins at $\sim 10.7 \AA$. The amount of intercalated $\mathrm{CO}_{2}$ then increases stepwise with increasing basal spacing (Figures 3a and 3b). Except with $\mathrm{Cs}^{+}$, the basal spacing at which intercalation begins is greater than the basal spacings of the fully collapsed structures.

In parallel, the computed immersion energies show an energy barrier to $\mathrm{CO}_{2}$ intercalation that decreases with increasing cation size for both the alkali and alkaline earth series (Figures 3c and 3d). This energy barrier is the difference between the maximum energy of the system (typically near 10.5 - $11.0 \AA$ ) and the value for the fully collapsed structure with the same cation. With $\mathrm{Cs}^{+}$, there is no energy barrier, and the immersion energy decreases 
continuously from that of the collapsed structure to the first energy minimum near $12.5 \AA$. With $\mathrm{K}^{+}, \mathrm{Rb}^{+}, \mathrm{Sr}^{2+}$, and $\mathrm{Ba}^{2+}$, the barrier is quite small, but it is much larger with $\mathrm{Li}^{+}, \mathrm{Na}^{+}, \mathrm{Mg}^{2+}$ and $\mathrm{Ca}^{2+}$. With $\mathrm{Li}^{+}, \mathrm{Na}^{+}, \mathrm{Mg}^{2+}$ and $\mathrm{Ca}^{2+}$, the global minimum energy structure is the collapsed state, whereas it is the monolayer structure near $12.5 \AA$ with $\mathrm{K}^{+}, \mathrm{Rb}^{+}, \mathrm{Cs}^{+}, \mathrm{Sr}^{2+}$ and $\mathrm{Ba}^{2+}$.

We interpret these results to show that $\mathrm{CO}_{2}$ should spontaneously enter the interlayer galleries of fully dehydrated and collapsed $\mathrm{K}^{+}, \mathrm{Rb}^{+}, \mathrm{Cs}^{+}, \mathrm{Sr}^{2+}$, and $\mathrm{Ba}^{2+}$ hectorite, but not $\mathrm{Li}^{+}$, $\mathrm{Na}^{+}, \mathrm{Mg}^{2+}$ and $\mathrm{Ca}^{2+}$ hectorite. This conclusion is in full agreement with the experimental XRD results above that show $\mathrm{CO}_{2}$ intercalation in Cs-hectorite but not Na-hectorite. Note that the computed immersion energies here are not free energies and do not include entropic effects. This could make a difference in interpreting relatively small immersion energy differences between the monolayer and bilayer structures of the $\mathrm{K}^{+}, \mathrm{Rb}^{+}, \mathrm{Cs}^{+}, \mathrm{Sr}^{2+}$, and $\mathrm{Ba}^{2+}$ systems, but are unlikely to be significant for interpreting the results for the $\mathrm{Li}^{+}, \mathrm{Na}^{+}, \mathrm{Mg}^{2+}$ and $\mathrm{Ca}^{2+}$ systems. The computed intercalation energies are consistent with the results of comparable GCMD calculations for $\mathrm{Na}-, \mathrm{NH}_{4}$, and Cs-montmorillonite, which show a large barrier to $\mathrm{CO}_{2}$ intercalation with $\mathrm{Na}^{+}$but essentially no barrier with $\mathrm{NH}_{4}{ }^{+}$and $\mathrm{Cs}^{+} .{ }^{51}$ This conclusion is also consistent with the free energy calculations by Makaremi et al. ${ }^{43}$, which show a large energy barrier for $\mathrm{CO}_{2}$ intercalation into Na-montmorillonite.

The relationship between the basal spacings and computed energies that highlight the need to prop open the interlayers of smectites that contain relatively small charge-balancing cations to allow $\mathrm{CO}_{2}$ intercalation, as observed in previous experimental and simulation studies. ${ }^{9-14,16-23,40-45,48}$ These studies have indicated that the small cations with high hydration energies, the interlayers needed to be propped open by some $\mathrm{H}_{2} \mathrm{O}$ molecules to incorporate $\mathrm{CO}_{2}$, and the maximum $\mathrm{CO}_{2}$ intercalation (maximum $\mathrm{CO}_{2} / \mathrm{CO}_{2}+\mathrm{H}_{2} \mathrm{O}$ ratio) occurs near the monolayer hydrate interlayer structure. ${ }^{9-14,40-45,48}$ To our knowledge, there have been no studies of $\mathrm{CO}_{2}$ intercalation in pillared clays, which are propped open by interlayer precipitates. 
For all the simulated systems here, the increase in interlayer $\mathrm{CO}_{2}$ content with increasing basal spacing shows 2 broad plateaus between 12.4-13.5 $\AA$ and 15.5-16.3 $\AA$ (Figures 3a and 3b), corresponding to monolayer and bilayer $\mathrm{CO}_{2}$ structures, respectively. In parallel, the immersion energies have broad minima at the same basal spacing ranges (Figures 3c and 3d). Basal spacings associated with monolayer $\mathrm{CO}_{2}$ adsorption were previously reported for Na-fluorohectorite exposed to gaseous $\mathrm{CO}_{2}$ at much lower temperature and pressure conditions (253 $\mathrm{K}$ and 15 bar) using XRD. ${ }^{67}$ For our hectorite simulations with $\mathrm{Li}^{+}, \mathrm{Na}^{+}, \mathrm{Mg}^{2+}$ and $\mathrm{Ca}^{2+}$, these monolayer and bilayer structures are metastable with respect to the collapsed structures, and for Na-hectorite interlayer adsorption of $\mathrm{CO}_{2}$ is not experimentally accessible. We expect fully dry Li-, Mg-, and Ca-hectorites to behave in the same way. As for the Cs-hectorite XRD experiments and simulations, the computational results suggest that dry hectorite exchanged with $\mathrm{K}^{+}, \mathrm{Rb}^{+}, \mathrm{Sr}^{2+}$, and $\mathrm{Ba}^{2+}$ should intercalate $\mathrm{CO}_{2}$ and expand. For the Cs-hectorite simulations reported here, the monolayer structure is the experimentally observed stable state, in agreement with the global energy minimum in the computed immersion energy at the monolayer structure compared to the bilayer structure. This is also the case with $\mathrm{Rb}^{+}, \mathrm{K}^{+}, \mathrm{Sr}^{2+}$ and $\mathrm{Ba}^{2+}$. However, with divalent cations, the immersion energy differences between the monolayer and bilayer structures are small.

For our systems with alkali cations, the computed interlayer $\mathrm{CO}_{2}$ content decreases as the size of the cation increases from $\mathrm{Li}^{+}$to $\mathrm{Cs}^{+}$. For the monolayer structures this decrease is from 2.7 to $1.8 \mathrm{CO}_{2}$ per unit cell, and for the bilayer structures, it is from 5.0 to 3.8 molecules per unit cell. In contrast, with the alkaline earth cations cation size has no effect on the amount of intercalated $\mathrm{CO}_{2}$, with all systems showing $\sim 2.6$ and $\sim 5.3 \mathrm{CO}_{2}$ per unit cell at the monolayer and bilayer spacings, respectively. The decreasing interlayer $\mathrm{CO}_{2}$ content with increasing ionic radii with the alkali metal cations correlates well with experimental and simulation studies of montmorillonite exposed to dry $\mathrm{CO}_{2}$ under identical thermodynamic conditions. ${ }^{51}$ In contrast, 
recent experimental study by Bowers et al. ${ }^{9}$ have reported that the interlayer $\mathrm{CO}_{2}$ content of Cs-hectorite exposed to $\mathrm{scCO}_{2}$ with increasing water content is greater than that of Nahectorite. This difference is probably due to the larger hydration energy of $\mathrm{Na}^{+}$causing more interlayer $\mathrm{H}_{2} \mathrm{O}$ adsorption leaving less open interlayer space for $\mathrm{CO}_{2}$ intercalation in the studies by Bowers et al. ${ }^{9}$ However, under dry $\mathrm{scCO}_{2}$ exposure, the smaller the size of the cation, the larger the interlayer space available for $\mathrm{CO}_{2}$ intercalation thus leading to higher $\mathrm{CO}_{2}$ content for Na- than Cs-hectorite.

In the current study, at any given basal spacing, the number of intercalated $\mathrm{CO}_{2}$ molecules per cation is always greater with the alkaline earth cations than with the alkali cations. As discussed in our previous experimental and simulation studies, ${ }^{9,19}$ this difference can be attributed to the smaller number of divalent cations required to compensate the hectorite layer charge, thereby increasing the interlayer space accessible for $\mathrm{CO}_{2}$ compared to smectites with monovalent cations. With alkali cations the plateau regions also become increasingly flat with increase in ionic size, whereas the plateau shapes are similar for all the alkaline earth cations. This is likely because the change in ion size is substantially greater for the alkali cation series $\left(\mathrm{Li}^{+}\right.$vs $\left.\mathrm{Cs}^{+}\right)$than the alkaline earth cation series $\left(\mathrm{Mg}^{2+}\right.$ vs $\left.\mathrm{Ba}^{2+}\right)$. The absence of substantial differences with the different alkaline earth cations despite the $\sim 160 \mathrm{~kJ} / \mathrm{mol}$ difference in the $\mathrm{CO}_{2}$ solvation energies between $\mathrm{Mg}^{2+}$ and $\mathrm{Ba}^{2+}$ supports the geometrical origin of this effect.

The energetic contributions from the cation-clay layer, cation- $\mathrm{CO}_{2}$, and $\mathrm{CO}_{2}$-clay layer interactions provide deeper insight into the origin of the dependence of the $\mathrm{CO}_{2}$ intercalation on the properties of the cation and demonstrate that the magnitude of the interaction between the cation and the clay T-O-T layers dominates this behavior (Figure 4). For both the alkali and alkaline earth cation series, the magnitude of the cation-clay layer interaction for the fully collapsed structures decreases (becomes less negative) with increasing cation size (Figures 4a 
and 4b). The energies at the collapsed basal spacings are the relevant comparators, since for each system expansion starts from this value. With the alkali cations, this energy varies from $-3675.3 \mathrm{~kJ} / \mathrm{mol}$ with $\mathrm{Li}^{+}$to $-3400.1 \mathrm{~kJ} / \mathrm{mol}$ with $\mathrm{Cs}^{+}$, and with the alkaline earth cations it varies $-3764.9 \mathrm{~kJ} / \mathrm{mol}$ with $\mathrm{Mg}^{2+}$ to $-3487.9 \mathrm{~kJ} / \mathrm{mol}$ with $\mathrm{Ba}^{2+}$. Importantly, the difference in the clay-cation interaction energies between the collapsed structures and the basal spacings at which intercalation begins $(\sim 11.0 \AA)$ is large for cations with high hydration energies and decreases with increasing cation size. Hence, there is a cost of $>\sim 150 \mathrm{~kJ} / \mathrm{mol}$ in the clay-cation interaction energies with $\mathrm{Li}^{+}, \mathrm{Na}^{+}, \mathrm{Mg}^{2+}$ and $\mathrm{Ca}^{2+}$ for any $\mathrm{CO}_{2}$ to intercalate, in contrast to $<\sim 60 \mathrm{~kJ} / \mathrm{mol}$ with the other cations. At monolayer spacings the clay-cation interaction energies are very similar for both the alkali and alkaline earth cations, and the differences at larger basal spacings are very small. Despite a need for only half the number of cations to compensate the layer charge with the alkaline earth cations vs. the alkali cations, the magnitude of the interaction energies for both types of cations with the clay surface are very similar. This similarity indicates that the divalent cations have a greater interaction energy per cation with the clay structure than the monovalent cations, as expected from the charge differences. For the cation- $\mathrm{CO}_{2}$ interactions at a given basal spacing, the interaction energies are negative and decrease (becomes less negative) with increasing cation size in each cation series. They are larger in general for the alkaline earth series (Figures 4c and 4d). Both these trends are expected based upon recently computed cation- $\mathrm{CO}_{2}$ solvation energies in $\mathrm{scCO}_{2}$ fluid. ${ }^{51,68}$ The interaction energies of $\mathrm{CO}_{2}$ molecules with the clay structure are slightly negative but do not vary greatly with the different alkaline and alkaline earth cations (Figures 4e and 4f). Together, these results show that the increase in the cation- $\mathrm{CO}_{2}$ interaction energy with decreasing cation size cannot overcome the decreasing cation-clay interaction energy in the absence of $\mathrm{H}_{2} \mathrm{O}$.

\section{Computed Interlayer Structure}


It is normally not possible to determine the detailed arrangement of the cations and fluid molecules in smectite interlayer galleries by diffraction methods due to static and dynamic structural disorder, and computed structures provide insight into the interlayer fluid structures. For the computed systems here, the atomic density profiles (ADPs) normal to the clay basal surface show that the average positions of the different species vary somewhat with the cation. For the monolayer structures here, the ADPs of $\mathrm{C}_{\mathrm{CO} 2}, \mathrm{O}_{\mathrm{CO} 2}$, and the cation are all centered at the middle of the interlayer at $\sim 2.8 \AA$ to $\sim 3.0 \AA$ from both basal surfaces and become narrower with increasing cation size in each series (Figures 5a-5i). The ADPs of $\mathrm{Li}^{+}, \mathrm{Na}^{+}$and $\mathrm{Mg}^{2+}$ are significantly broader than those of the other cations, reflecting their relatively small size and ability to move perpendicular to the basal surfaces. The ADPs of the intercalated $\mathrm{CO}_{2}$ molecules do not vary significantly with cation size, and both $\mathrm{O}_{\mathrm{CO} 2}$ and $\mathrm{C}_{\mathrm{CO} 2}$ share the same plane as the cations, centered at $\sim 2.9 \AA$ from the two basal surfaces. With the alkali cations, the $\mathrm{O}_{\mathrm{CO} 2}$ and $\mathrm{C}_{\mathrm{CO} 2}$ intensities decrease with increasing cation size due to the decreasing amount of intercalated $\mathrm{CO}_{2}$ (Figures 5a-5e). They do not vary with the different alkaline earth cations, reflecting the independence of the amount of intercalated $\mathrm{CO}_{2}$ on the cation for this series. This result is consistent with much of the $\mathrm{CO}_{2}$ being located in free volume in the interlayer rather than being coordinated to the cations, as the energetic results above suggest (Figures $5 f-5 i$ ).

The average orientation of the O-C-O axis of the intercalated $\mathrm{CO}_{2}$ molecules lies parallel to the basal surfaces with all the cations (Figures 6a and 6b), as expected from the ADPs of $\mathrm{O}_{\mathrm{CO} 2}$ and $\mathrm{C}_{\mathrm{CO} 2}$ and in agreement with the ${ }^{13} \mathrm{C}$ NMR results above. However, the range of angles probed by the O-C-O vector is somewhat larger with the alkali cations $\left(45^{\circ}-135^{\circ}\right)$ than with the alkaline earth cations $\left(55^{\circ}-125^{\circ}\right)$, indicating slightly more dynamically restricted local structural environment with the alkaline earth cations. This difference is probably due to the larger interlayer $\mathrm{CO}_{2}$ contents with the alkaline earth cations leading to less interlayer space. Visual analysis of the trajectories shows that the individual $\mathrm{CO}_{2}$ molecules spend part of the 
time oriented parallel to the clay layers and part of the time wobbling. The fraction of the time spent wobbling decreases with increasing cation size with the alkali cations, but does no change significantly with the alkaline earth cations (Figure 6).

As expected, the computed mean interatomic distance between the cations and $\mathrm{CO}_{2}$ molecules increases with increasing cation size in the order $\mathrm{Cs}^{+}>\mathrm{Ba}^{2+}>\mathrm{Na}^{+}>\mathrm{Mg}^{2+}$ (Figures 7a -7d). Similarly, cations with small ionic radii are coordinated to the basal hectorite surface at shorter interatomic M-Ob distances $\left(<2.5 \AA\right.$ for $\mathrm{Na}^{+}$and $\left.\mathrm{Mg}^{2+}\right)$ than $\mathrm{Cs}^{+}(\sim 3.0 \AA)$. The mean interatomic distances between $\mathrm{CO}_{2}$ molecules and surface oxygen atoms $\left(\mathrm{O}_{\mathrm{b}}\right)$, however, do not change with changing cation size. Paralleling the cation-oxygen interatomic distances, the running coordination numbers (RCN) between all the interlayer species vary considerably with the size of the cation. For the monolayer structures, the total coordination of $\mathrm{CO}_{2}$ molecules by cations, surface $\mathrm{O}_{\mathrm{b}}$ atoms, and other $\mathrm{CO}_{2}$ molecules is $\sim 15.2$ for $\mathrm{Na}^{+}, \mathrm{Cs}^{+}$, and $\mathrm{Mg}^{2+}$ but is $\sim 17.0$ for $\mathrm{Ba}^{2+}$ ions. The RCN of cations with $\mathrm{O}_{\mathrm{b}}$ atoms, however, increases from $\sim 2$ for $\mathrm{Na}^{+}$ and $\mathrm{Mg}^{2+}$ to $\sim 6.5$ and $~ 7.5$ for $\mathrm{Ba}^{2+}$ and $\mathrm{Cs}^{+}$, respectively. The adsorption structure and $\mathrm{RCN}$ values for Na- and Cs-hectorites are in excellent agreement with previous studies on hectorites under ambient and elevated $T$ and $P$ conditions. ${ }^{14,17,47}$

The two-dimensional density maps (also called planar atomic density distributions, or PADDs) for the monolayer structures show that the differences in the RCNs for different cations are the result of significantly different local adsorption environments (Figures 8a-8d). The $\mathrm{Na}^{+}$and $\mathrm{Mg}^{2+}$ ions are located predominately between two $\mathrm{O}_{\mathrm{b}}$ atoms, one on each basal surface giving rise to the $\mathrm{O}_{b} \mathrm{RCN}$ of $\sim 2$. For Na-hectorite (Figure $8 \mathrm{a}$ ), the sets of three neighboring site maxima represent the same $\mathrm{Na}^{+}$ion (blue) that is hopping between different sites, illustrating a potential pathway for $\mathrm{Na}^{+}$diffusion along these narrow channels unhindered by intercalated $\mathrm{CO}_{2}$. Likewise, the pairs of maxima for $\mathrm{Mg}^{2+}$ (Figure 8c) represent the same ion, but in this case the site hopping is more hindered by the increased number of intercalated 
$\mathrm{CO}_{2}$ molecules. As a result, the arrangement of $\mathrm{CO}_{2}$ molecules is more ordered in Mg-hectorite than in Na-hectorite, where the $\mathrm{CO}_{2}$ molecules adsorb in narrow channels formed by $\mathrm{Na}^{+}$ions and wobble between adjacent hectorite surfaces. This difference correlates well with the more restricted orientation distribution for $\mathrm{CO}_{2}$ molecules with $\mathrm{Mg}^{2+}$ than with $\mathrm{Na}^{+}$. Nonetheless, there are on average four $\mathrm{CO}_{2}$ molecules around both $\mathrm{Na}^{+}$and $\mathrm{Mg}^{2+}$, consistent with the RCN values (Figures 7a and 7b). For both Na- and Mg-hectorite, the intercalated $\mathrm{CO}_{2}$ molecules form small clusters, with their arrangement predominantly in a slipped parallel geometry. A small fraction of $\mathrm{CO}_{2}$ molecules in these clusters are in a distorted T-shaped arrangement, particularly in Mg-hectorite because of its larger number of intercalated $\mathrm{CO}_{2}$ molecules. A Tshaped arrangement is highly unlikely for Na-hectorite because of the narrow channels formed by the $\mathrm{Na}^{+}$ions and $\mathrm{CO}_{2}$ molecules. For both $\mathrm{Na}$ - and $\mathrm{Mg}$-hectorite here, the intercalated $\mathrm{CO}_{2}$ molecules are adsorbed with one $\mathrm{O}_{\mathrm{CO} 2}$ located near the center of a ditrigonal cavity with the other above a neighboring Si tetrahedron.

Surprisingly, the adsorption structures of $\mathrm{CO}_{2}$ molecules in Cs- and Ba-hectorite are generally similar to that in Na- and Mg-hectorite, despite the considerably different ionic sizes and interlayer $\mathrm{CO}_{2}$ contents. Importantly, the RCNs of intercalated $\mathrm{CO}_{2}$ with surface $\mathrm{O}_{\mathrm{b}}$ atoms is 7-8 with all cations because of the similar adsorption structures described above. The RCN of $\mathrm{CO}_{2}$ molecules with interlayer cations is $\sim 4$ for $\mathrm{Na}^{+}-\mathrm{Cs}^{+}$- and $\mathrm{Mg}^{2+}$ - and is $\sim 5$ with $\mathrm{Ba}^{2+}$, in agreement with the PADDs in Figures 8a-8d. Similarly, the RCN between intercalated $\mathrm{CO}_{2}$ molecules varies significantly between the structures with alkali cations ( 3.5-4) and alkaline earth cations ( 5-6) and is due to higher interlayer $\mathrm{CO}_{2}$ content in the latter case. The contour patterns for $\mathrm{CO}_{2}$ molecules in Cs-hectorite are more disordered than in the other models due to the lower $\mathrm{CO}_{2} /$ cation ratio and subsequently larger free interlayer space available for librational/wobbling motion. The coordination environments of the $\mathrm{Cs}^{+}$and $\mathrm{Ba}^{2+}$ ions, however, are quite different (Figures $8 \mathrm{~b}$ and $8 \mathrm{~d}$ ). The large RCN of $\mathrm{Cs}^{+}$with $\mathrm{O}_{\mathrm{b}}$ atoms $(\sim 7.5)$ 
is due to the fact that on average the $\mathrm{Cs}^{+}$ions are located above the center of a ditrigonal cavity of one surface and above a Si tetrahedron on the opposite surface. The $\mathrm{Cs}^{+}$ions oscillate between the centers of different ditrigonal cavities and above different Si tetrahedra the, resulting in the disordered contours in Figure $8 \mathrm{~b}$. In contrast, the $\mathrm{Ba}^{2+}$ ions are adsorbed between Si tetrahedra from both basal surfaces, leading to the average RCN value of $\sim 6.0$.

The computed $\mathrm{CO}_{2}$ orientations and locations in the PADDS are in excellent agreement with the ${ }^{13} \mathrm{C}$ NMR results for Cs-hectorite, which show a restricted environment for the $\mathrm{CO}_{2}$ molecules in which the time averaged O-C-O vector is parallel to the basal surfaces and the molecules undergo rapid rotation or libration (frequencies $>\sim 10^{5} \mathrm{~Hz}$ ) about an axis perpendicular to their O-C-O axies. The PADD results show that on the 10 ns time scale of the simulations the motion is best thought of as hindered libration rather than free rotation. The tight contours in the PADDs show that the positions of the $\mathrm{O}_{\mathrm{CO} 2}$ are typically quite restricted, even with $\mathrm{Cs}^{+}$. On the $\sim$ ms time scale of probed by the ${ }^{13} \mathrm{C}$ NMR line shapes, however, this may not be true. As shown in our previous experimental study of variably humidified $\mathrm{CO}_{2}$ /hectorite interactions, ${ }^{9}$ the absence of $\mathrm{CO}_{2}$ molecules with $\mathrm{O}-\mathrm{C}-\mathrm{O}$ vectors near $0^{\circ}$ and $180^{\circ}$ (Figure 6) shows that they never experience isotropic reorientation because they are never oriented perpendicular to the basal surfaces.

\section{Residence times}

The dynamic interaction among the interlayer species and $\mathrm{O}_{\mathrm{b}}$ atoms of the basal surfaces can be quantitatively characterized by the computed mean residence times, which for our systems decrease with increasing cation size for all interatomic pairs (Table 1). Overall, the mean residence times are at least twice as long with smaller cations $\left(\mathrm{Li}^{+}, \mathrm{Na}^{+}, \mathrm{Mg}^{2+}, \mathrm{Ca}^{2+}\right)$ than with larger cations $\left(\mathrm{K}^{+}, \mathrm{Rb}^{+}, \mathrm{Cs}^{+}\right.$and $\left.\mathrm{Ba}^{2+}\right)$. This relationship holds for both the intermittent residence times, $c(t)$, which allow for the possibility that individual atomic pairs 
can re-coordinate after becoming separated during the simulation, and the continuous residence times, $C(t)$, which do not allow such re-coordination. ${ }^{33,35,48}$ Here, the intermittent residence times are typically about an order of magnitude longer than the continuous ones, as also reported in our previous studies of hydrated interlayers and hectorite exposed to $\mathrm{H}_{2} \mathrm{O}$ saturated $\mathrm{scCO}_{2} \cdot{ }^{33,35,48}$ The $c(t)$ and $C(t)$ values for cation- $\mathrm{O}_{\mathrm{b}}$ pairs are consistently longer than those for cation- $\mathrm{O}_{\mathrm{CO} 2}$ and $\mathrm{O}_{\mathrm{b}}-\mathrm{O}_{\mathrm{CO} 2}$ coordination, indicating that interactions between cations and basal surfaces are the principal controls of the interlayer structure and dynamics. This conclusion is consistent with the energetic results above, which show that the extent of $\mathrm{CO}_{2}$ intercalation is strongly dependent on cation-clay interactions (Figures 4a-4f). As the size of interlayer cations increases, the residence times for cation- $\mathrm{O}_{\mathrm{b}}$ pairs decreases by an order of magnitude paralleling the expected stronger coordination of smaller cations with clay surfaces, which are dominated by electrostatic interactions. This result is in good agreement with the atomic density maps for especially the alkali cations, which show much more ordered contours for $\mathrm{Na}^{+}$ than for $\mathrm{Cs}^{+}$(Figures 8a and 8b). This difference is less pronounced with the divalent cations, because their higher charge leads to overall stronger coordination with the surface. The cation$\mathrm{O}_{\mathrm{b}}$ residence times are in reasonable agreement with previous simulation studies of hectorite under ambient conditions. ${ }^{33,35}$ The cation- $\mathrm{CO}_{2}$ residence times are longer than $\mathrm{O}_{\mathrm{b}}-\mathrm{CO}_{2}$ residence times, particularly for smaller ions, consistent with their $\mathrm{CO}_{2}$ solvation energies. ${ }^{51,68}$ The difference in cation- $\mathrm{CO}_{2}$ and $\mathrm{O}_{\mathrm{b}}-\mathrm{CO}_{2}$ residence times decreases with increasing cation size, especially with the alkali cations.

\section{Comparison of Na- and Cs-hectorite}

The effects of the exchangeable cations on the structure and energetics of $\mathrm{CO}_{2}$ molecules intercalated in smectites and the connections to the experimental results are well illustrated by comparing the specific details of the Na- and Cs-hectorite systems. The collapsed interlayer distances for Na- (9.5 $\AA$ ) and Cs-hectorite (10.7 $\AA$ ) computed from our simulations 
are in good agreement with the values obtained in XRD measurements under vacuum conditions (9.8 $\AA$ and Cs-11.08 $\AA$, respectively) and also in good agreement with published computed values, which vary slightly depending on the interatomic potentials used in the simulations. ${ }^{12,14,16,17,20,69,70,71}$

Upon exposure to dry $\mathrm{scCO}_{2}$ at $323 \mathrm{~K}$ and 90 bar, the XRD data indicate interlayer expansion for Cs-hectorite but not for Na-hectorite. This is in excellent agreement with our simulations that show that the collapsed structure is the most energetically favorable state for Na-hectorite (Figure 3c). In contrast, there is no energy barrier for Cs-hectorite, and this system favors interlayer expansion when in contact with dry $\mathrm{scCO}_{2}$. Our simulations also indicate that despite the stronger interaction energy between $\mathrm{Na}^{+}$and $\mathrm{CO}_{2}$ molecules $(-95 \mathrm{~kJ} / \mathrm{mol})$ than between $\mathrm{Cs}^{+}$and $\mathrm{CO}_{2}$ molecules $(-30 \mathrm{~kJ} / \mathrm{mol}), \mathrm{CO}_{2}$ intercalates in Cs-hectorite because the stronger cation-clay interactions with $\mathrm{Na}^{+}$result in a much larger energy cost for expansion from the collapsed to the monolayer structure $(\sim 400 \mathrm{~kJ} / \mathrm{mol})$ than with $\mathrm{Cs}^{+}(\sim 190 \mathrm{~kJ} / \mathrm{mol})$. Thus, the energy difference for the cation-clay interactions between the collapsed state and the basal spacing at which $\mathrm{CO}_{2}$ intercalation starts is $\sim 175 \mathrm{~kJ} / \mathrm{mol}$ with $\mathrm{Na}^{+}$and only $\sim 35 \mathrm{~kJ} / \mathrm{mol}$ with $\mathrm{Cs}^{+}$(see Figure 4a). Because of the small energy barrier, $\mathrm{CO}_{2}$ intercalation is favourable in Cs-hectorite, and not in Na-hectorite. These results indicate that the cation-clay interactions play a critical role during $\mathrm{CO}_{2}$ intercalation.

\section{Conclusions}

The intercalation of $\mathrm{CO}_{2}$ in the interlayers of the smectite clay hectorite with a range of mono- and divalent cations in contact with dry $\mathrm{scCO}_{2}$ at $323 \mathrm{~K}$ and 90 bar was quantitatively analyzed by GCMD simulations and in situ XRD and NMR experiments. The GCMD results show that clays containing small charge compensating cations, do not spontaneously incorporate $\mathrm{CO}_{2}$ in their interlayers when exposed to dry $\mathrm{scCO}_{2}$, but that those with larger exchangeable cations do. The thermodynamic energy barriers between the collapsed state of 
the clay structure and the onset of $\mathrm{CO}_{2}$ intercalation are large with small cations and decrease with increasing cation size. With $\mathrm{Li}^{+}, \mathrm{Na}^{+}, \mathrm{Mg}^{2+}$, and $\mathrm{Ca}^{2+}$, the fully collapsed state has the global energy minimum, but with $\mathrm{K}^{+}, \mathrm{Rb}^{+}, \mathrm{Cs}^{+}, \mathrm{Sr}^{2+}$, and $\mathrm{Ba}^{2+}$ the monolayer state has the global energy minimum, suggesting that hectorite with these cations should spontaneously intercalate $\mathrm{CO}_{2}$ and expand but that with the smaller cations it should not. This conclusion is in good agreement with the experimental observation that Na-hectorite does not incorporate $\mathrm{CO}_{2}$ under these conditions but that Cs-hectorite does. These results are also in good agreement with experimental and GCMD results showing that the similar smectite mineral montmorillonite incorporates dry $\mathrm{CO}_{2}$ and expands with interlayer $\mathrm{NH}_{4}{ }^{+}$and $\mathrm{Cs}^{+}$, but not with $\mathrm{Na}^{+}$. A detailed quantitative analysis of different contributions to the total interaction energies in the investigated systems demonstrates that the structural and energetic characteristics of interlayer expansion with dry $\mathrm{scCO}_{2}$ are largely controlled by the strength of the interactions between the cations and the clay T-O-T structure. This is unlike the case of $\mathrm{H}_{2} \mathrm{O}$ intercalation, where the hydration energy of cations dominates the interlayer expansion. . $3,35^{3}$

Structurally, irrespective of the cation size, charge and $\mathrm{CO}_{2}$ solvation energy, at monolayer basal spacings the computed average positions of the intercalated $\mathrm{CO}_{2}$ molecules and the cations are all at the mid-plane of the interlayer. Both the ${ }^{13} \mathrm{C}$ NMR spectra and GCMD simulations show that the intercalated $\mathrm{CO}_{2}$ molecules are oriented on average with their O-C-O axies parallel to the basal hectorite surfaces. These NMR results for Cs-hectorite show restricted dynamics for the interlayer $\mathrm{CO}_{2}$ in which they undergo rapid (frequency $>\sim 10^{5} \mathrm{~Hz}$ ) rotation or libration around an axis perpendicular to their long molecular axies. The GCMD calculations suggest that on the time scale of our simulations ( $10 \mathrm{~ns})$ this is principally librational hopping among reasonably well-defined sites. The GCMD results suggest that aggregation of the interlayer $\mathrm{CO}_{2}$ molecules results in both slipped parallel and T-shaped arrangements with slipped parallel dominant. The number of intercalated $\mathrm{CO}_{2}$ molecules is 
larger for interlayers with higher charge cations due to the larger free interlayer space available for $\mathrm{CO}_{2}$ intercalation due to the smaller number of charge compensating interlayer cations present. Since the cation-clay interactions dominate the thermodynamics of interlayer expansion with dry $\mathrm{CO}_{2}$, the expansion behavior of smectites with different layer charges or positions of isomorphic substitution (e.g., tetrahedral Al for Si substitution vs. dominantly the octahedral substitution in hectorite and montmorillonite) could be quite different than that discussed here.

\section{Acknowledgements}

All the calculations in this work were performed using computational resources at the National Energy Research Scientific Computing Center, which is supported by the Office of Science of the U.S. Department of Energy under ECARP No. m1649. The authors acknowledge iCER computational facility at Michigan State University for additional computational resources. The work was supported by the United States Department of Energy, Office of Science, Office of Basic Energy Sciences, Chemical Sciences, Biosciences, and Geosciences Division through the sister grants DE-FG02-10ER16128 (Bowers, P.I.) and DE-FG0208ER15929 (Kirkpatrick, P.I.), as well as through its Geosciences program at Pacific Northwest National Laboratory (J.S.L.). H.T.S. was supported by the DOE Office of Fossil Energy at PNNL through the National Energy Technology Laboratory, Morgantown, West Virginia. A.G.K. acknowledges the support of the industrial chair "Storage and Disposal of Radioactive Waste” at the IMT-Atlantique, funded by ANDRA, Areva, and EDF, and of the European Union's Horizon 2020 research and innovation program under grant agreement No. 640979.

\section{Notes}

The authors declare no competing financial interest. 


\begin{tabular}{cccc}
\hline Cation & Cation-Ob & Cation-Oco2 & Ob-Oco2 \\
\hline \multicolumn{4}{c}{$c(t): C(t)$} \\
$\mathrm{Li}^{+}$ & $10.4: 0.81$ & $6.3: 0.65$ & $3.1: 0.29$ \\
$\mathrm{Na}^{+}$ & $7.7: 0.54$ & $3.8: 0.42$ & $2.4: 0.21$ \\
$\mathrm{~K}^{+}$ & $2.1: 0.31$ & $1.9: 0.29$ & $1.1: 0.13$ \\
$\mathrm{Rb}^{+}$ & $0.9: 0.14$ & $1.1: 0.09$ & $0.9: 0.08$ \\
$\mathrm{Cs}^{+}$ & $0.7: 0.08$ & $0.8: 0.02$ & $0.8: 0.05$ \\
\hline $\mathrm{Mg}^{2+}$ & $12.1: 1.0$ & $8.4: 0.64$ & $5.5: 0.31$ \\
$\mathrm{Ca}^{2+}$ & $8.8: 0.79$ & $6.2: 0.48$ & $3.8: 0.24$ \\
$\mathrm{Sr}^{2+}$ & $5.2: 0.51$ & $4.1: 0.34$ & $2.1: 0.15$ \\
$\mathrm{Ba}^{2+}$ & $3.1: 0.35$ & $2.5: 0.25$ & $1.3: 0.12$ \\
\hline
\end{tabular}

Table 1. Calculated intermittent $c(t)$ and continuous $C(t)$ residence times (ns) for different atomic pairs for monolayer basal spacing (12.4 $\AA$ ) in the interlayers of hectorite with different charge compensating cations at $323 \mathrm{~K}$ and 90 bar. 

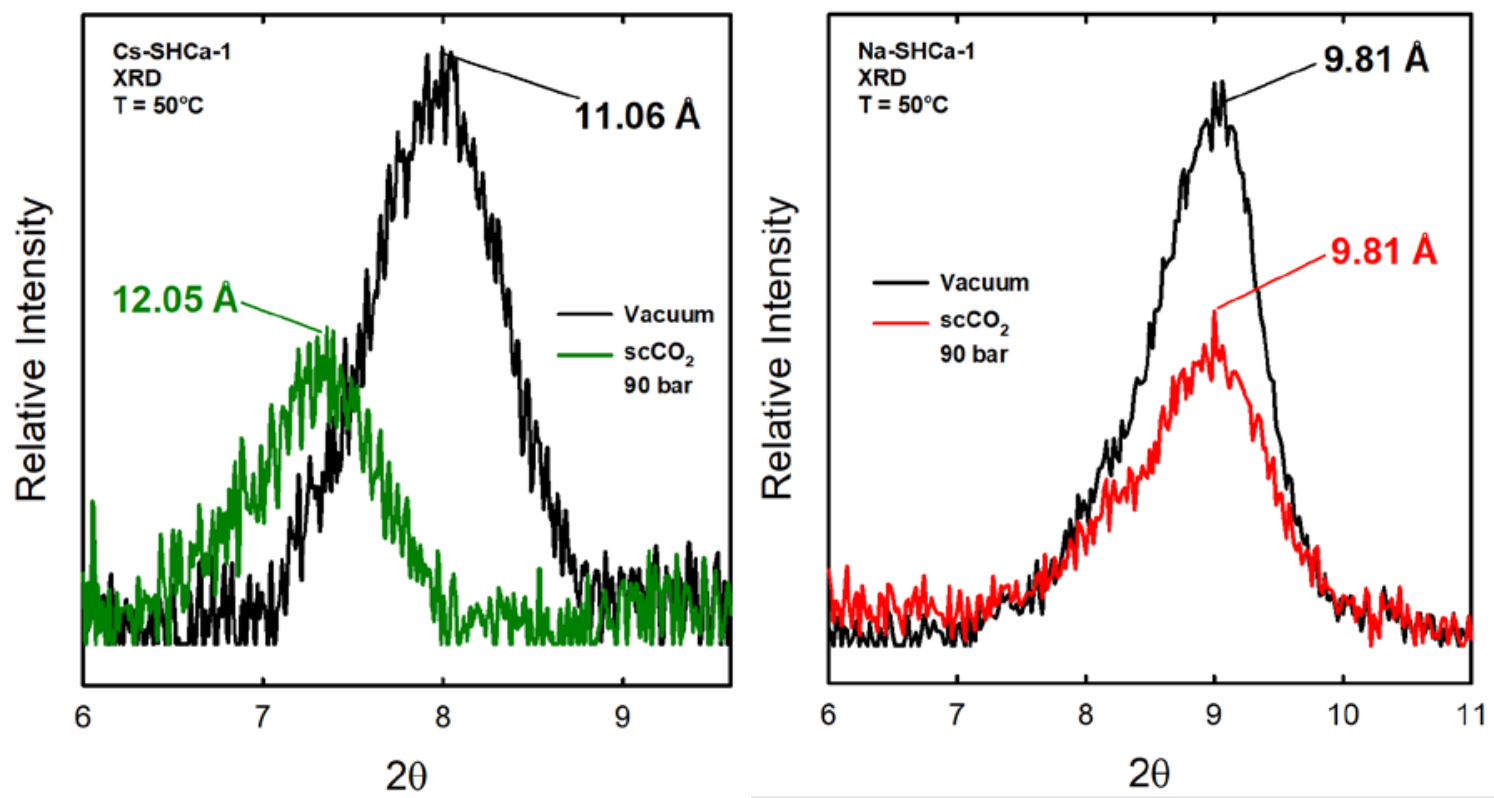

Figure 1. X-ray diffraction tracings of the Cs-SHCa-1 (left) and the Na-SHCa-1 (right) clay under vacuum $\left(10^{-3}\right.$ Torr, $\left.323 \mathrm{~K}\right)$ and during exposure to 90 bar $\mathrm{scCO}_{2}$ at $323 \mathrm{~K}$. Note that the smaller peak intensities in the samples exposed to $\mathrm{scCO}_{2}$ are due to signal attenuation by the dense $\mathrm{CO}_{2}$ fluid. 


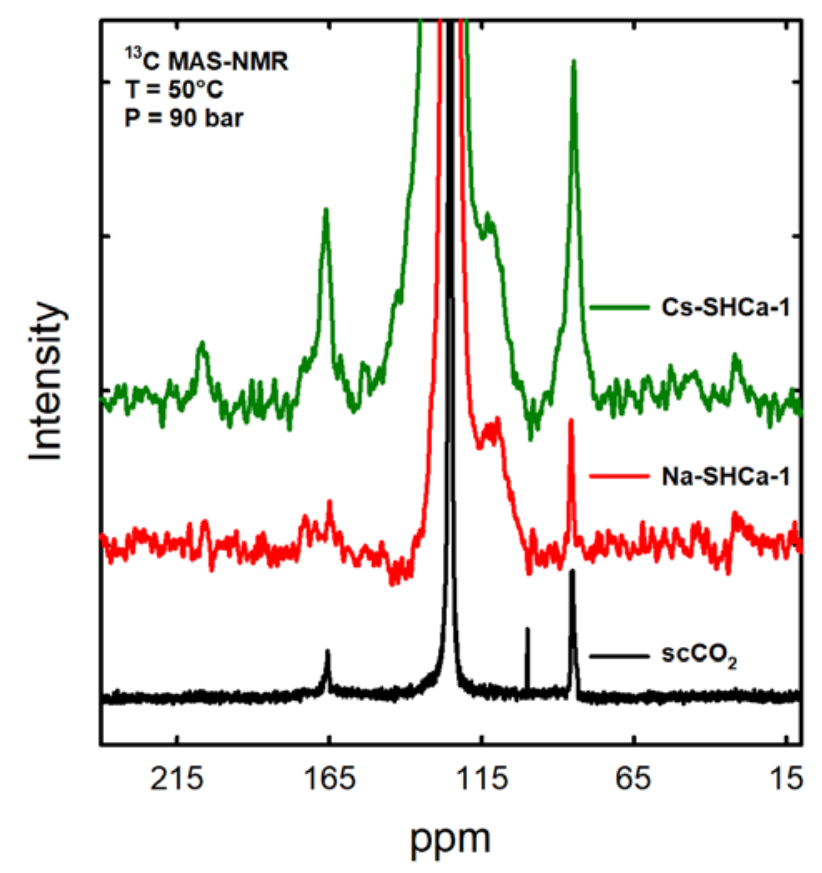

Figure 2. ${ }^{13} \mathrm{C}$ MAS NMR spectra Cs-SHCa-1 in $\mathrm{scCO}_{2}$ (top), Na-SHCa-1 in scCO $\mathrm{sCO}_{2}$ (middle), and a rotor only filled with $\mathrm{scCO}_{2}$, all at 90 bar pressure and $323 \mathrm{~K}$. The broad peak near $110 \mathrm{ppm}$ is the ${ }^{13} \mathrm{C}$ background of the NMR probe, and the narrow singularity near $100 \mathrm{ppm}$ reflects a DC offset in the receiver channels. 

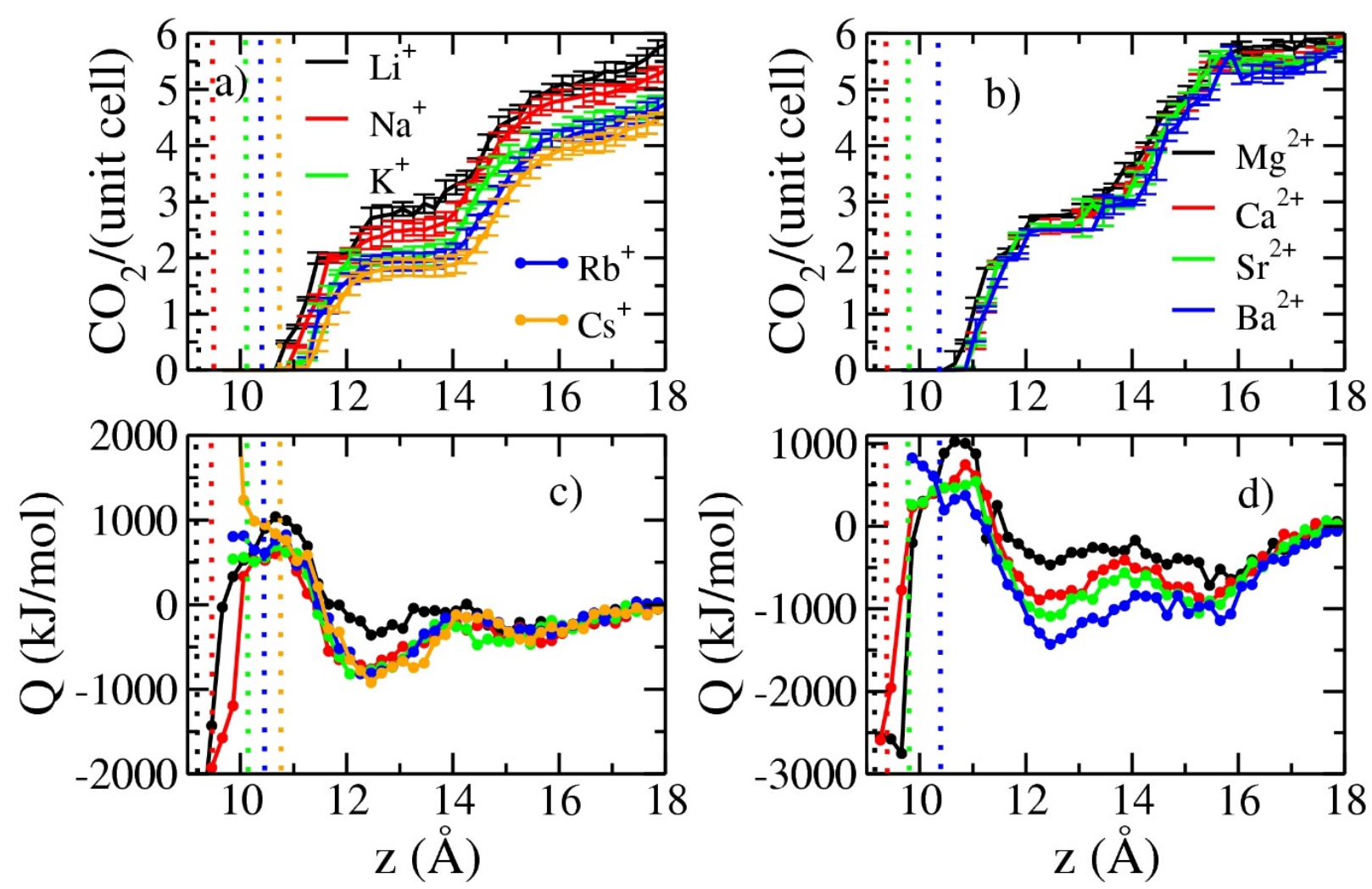

Figure 3. Average number of intercalated $\mathrm{CO}_{2}$ molecules (per unit cell) and computed immersion energies for hectorite models with different charge compensating cations as functions of interlayer basal spacing at $323 \mathrm{~K}$ and 90 bar. Dotted vertical lines indicate the collapsed interlayer distances for every cations used in our study. The reference state for computing the immersion energies is the $18.0 \AA$ basal spacing. 

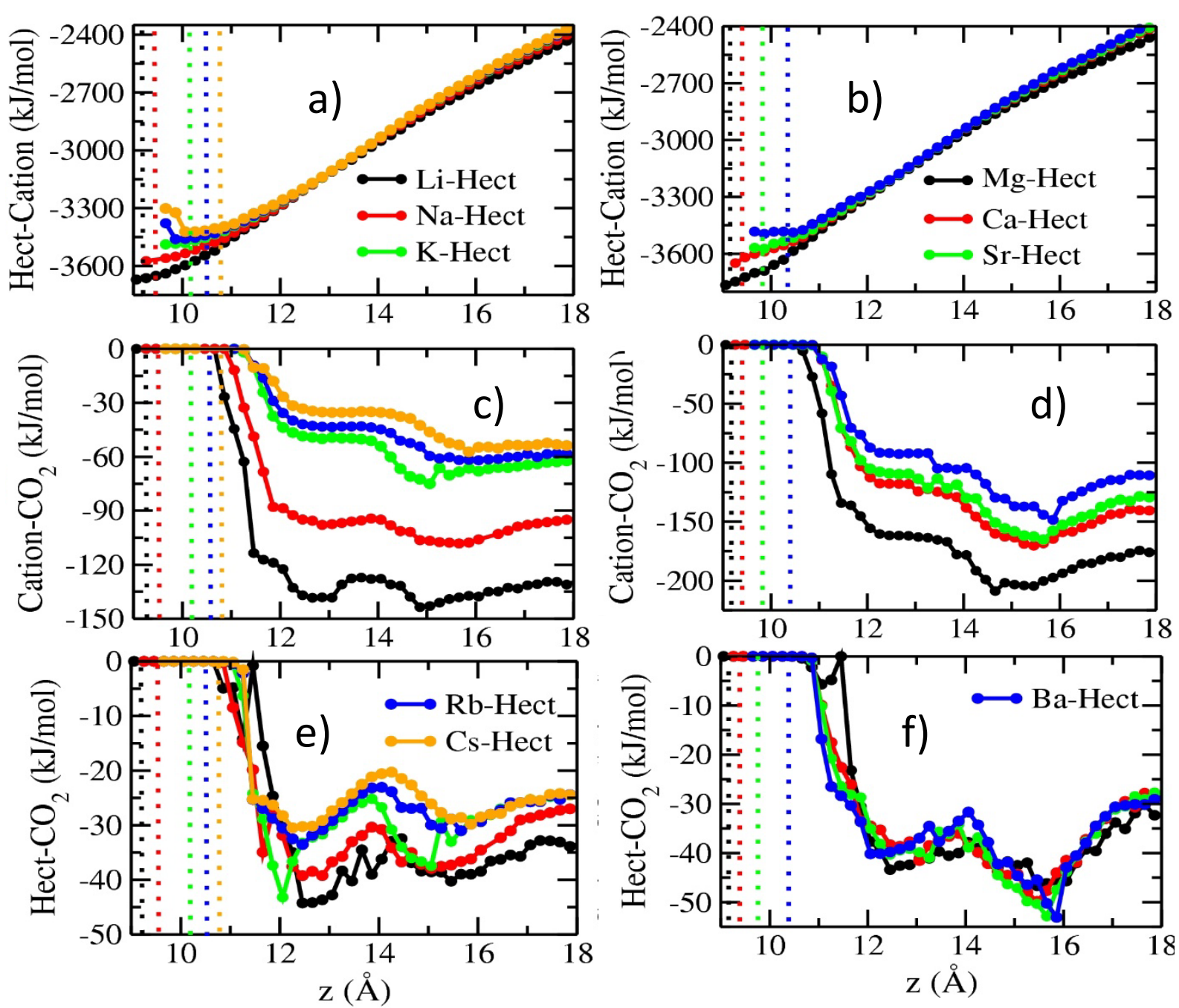

Figure 4. Computed variation in interaction energies between 3 different pairs (HectoriteCation (top), Cation- $\mathrm{CO}_{2}$ (middle), Hectorite- $\mathrm{CO}_{2}$ (bottom)) as functions of interlayer spacing using hectorite with different of mono- and di-valent cations at $323 \mathrm{~K}$ and 90 bar. Dotted vertical lines indicate the collapsed interlayer distances for every cations used in our study. 

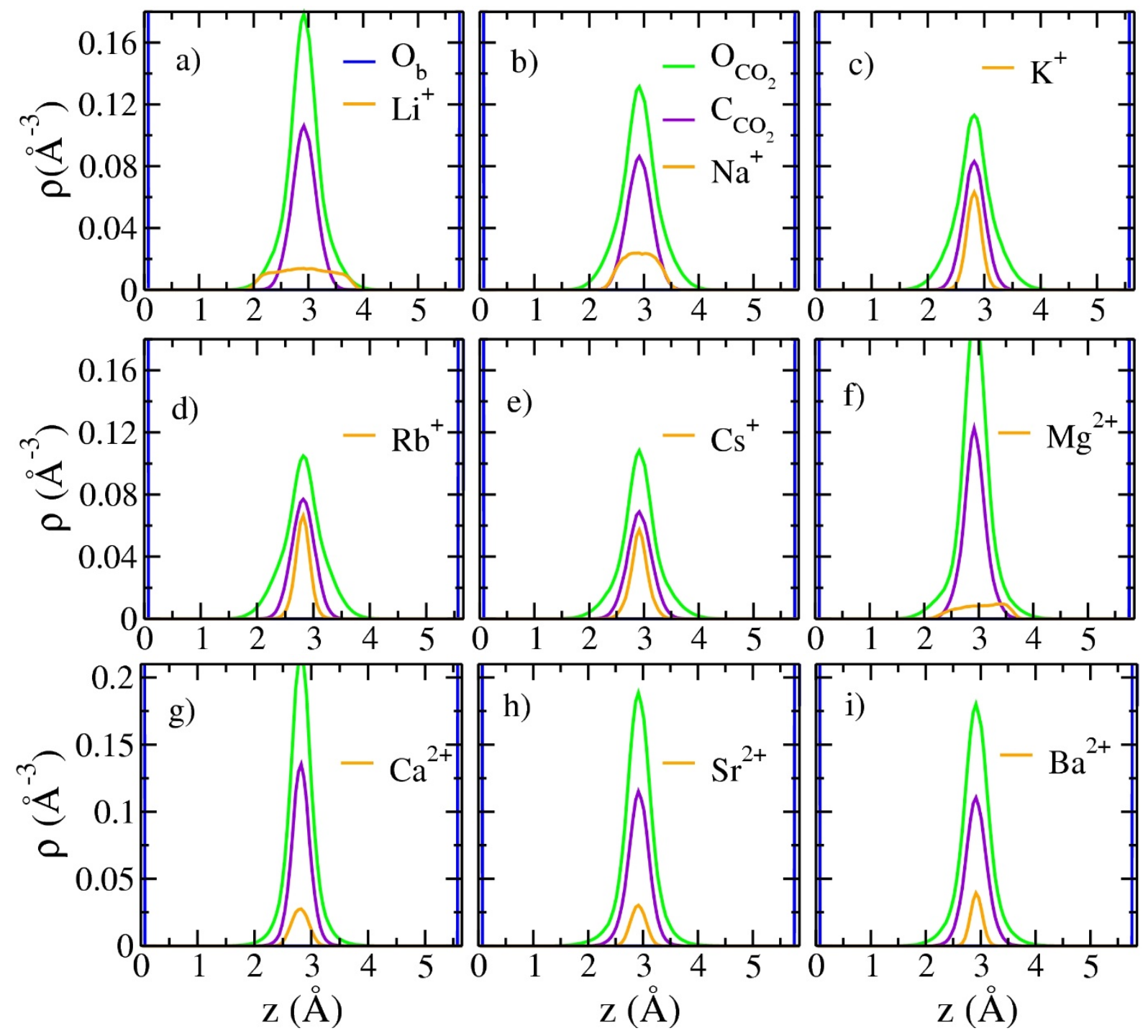

Figure 5. Computed atomic density profiles of $\mathrm{O}_{\mathrm{b}}$ (dark blue vertical lines), interlayer monoand divalent cations (orange), $\mathrm{O}_{\mathrm{CO} 2}$ (green) and $\mathrm{C}_{\mathrm{CO} 2}$ (violet) of hectorite as functions of distance from the basal clay surface at monolayer distances (12.4 $\AA$ ) under conditions of $323 \mathrm{~K}$ and 90 bar. 


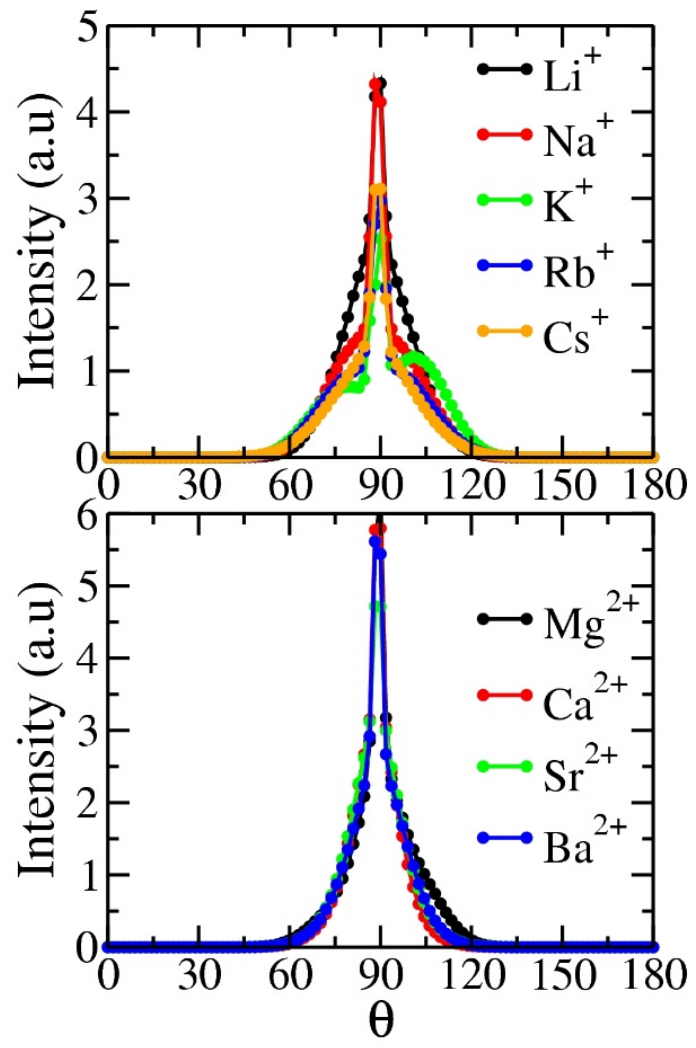

Figure 6. Computed orientational distributions of intercalated $\mathrm{CO}_{2}$ molecules in the interlayers of hectorite at monolayer distances under $323 \mathrm{~K}$ and 90 bar conditions with different charge compensating cations. $\Theta$ is the angle between the O-O vector of a $\mathrm{CO}_{2}$ molecule and the normal to the hectorite basal surface. Top panel monovalent cations: Bottom panel - divalent cations. 

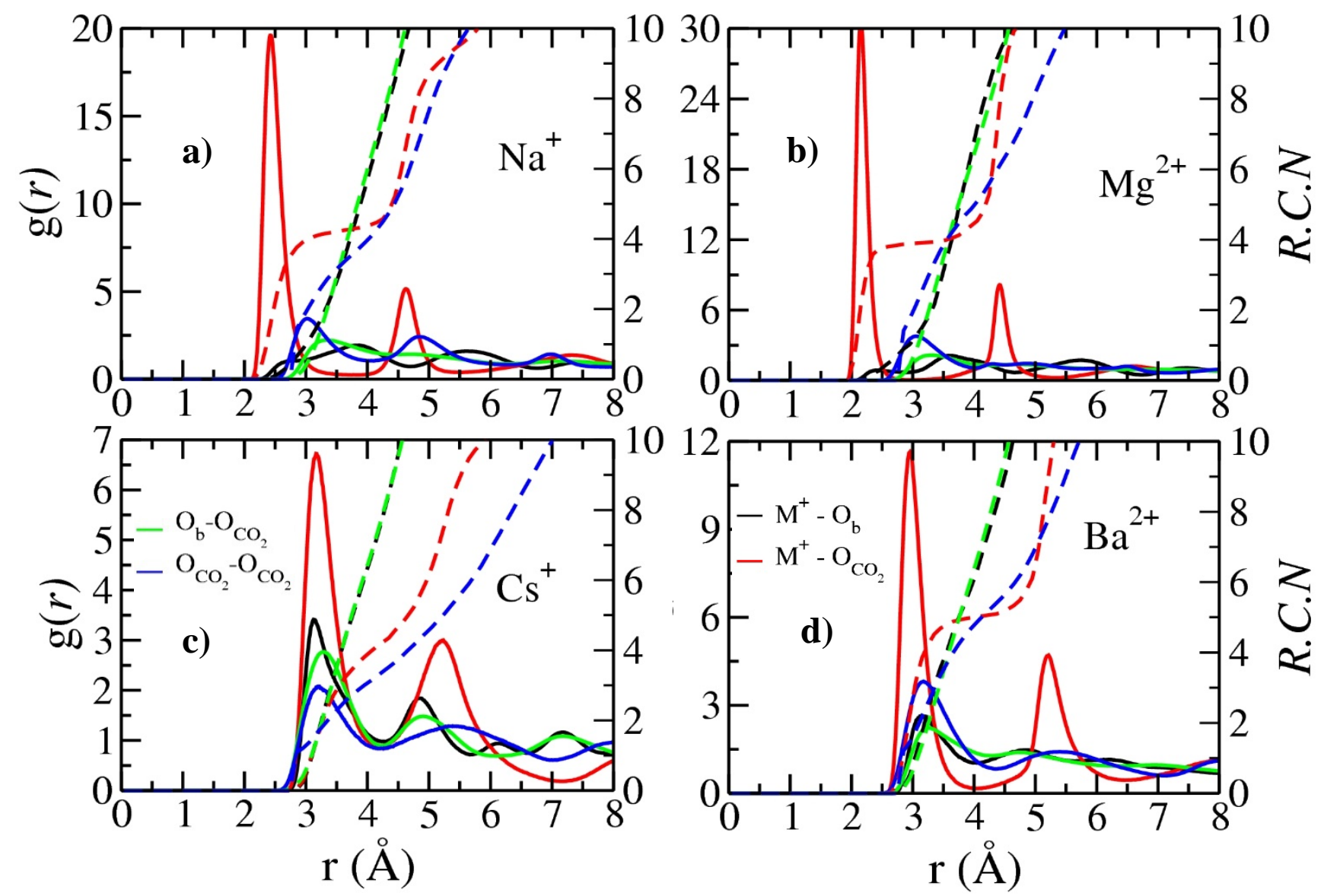

Figure 7. Radial distribution functions (RDFs, solid lines) and corresponding running coordination numbers (RCNs, dashed lines) for different atomic pairs in the interlayers of hectorite at monolayer distances under $323 \mathrm{~K}$ and 90 bar conditions. 

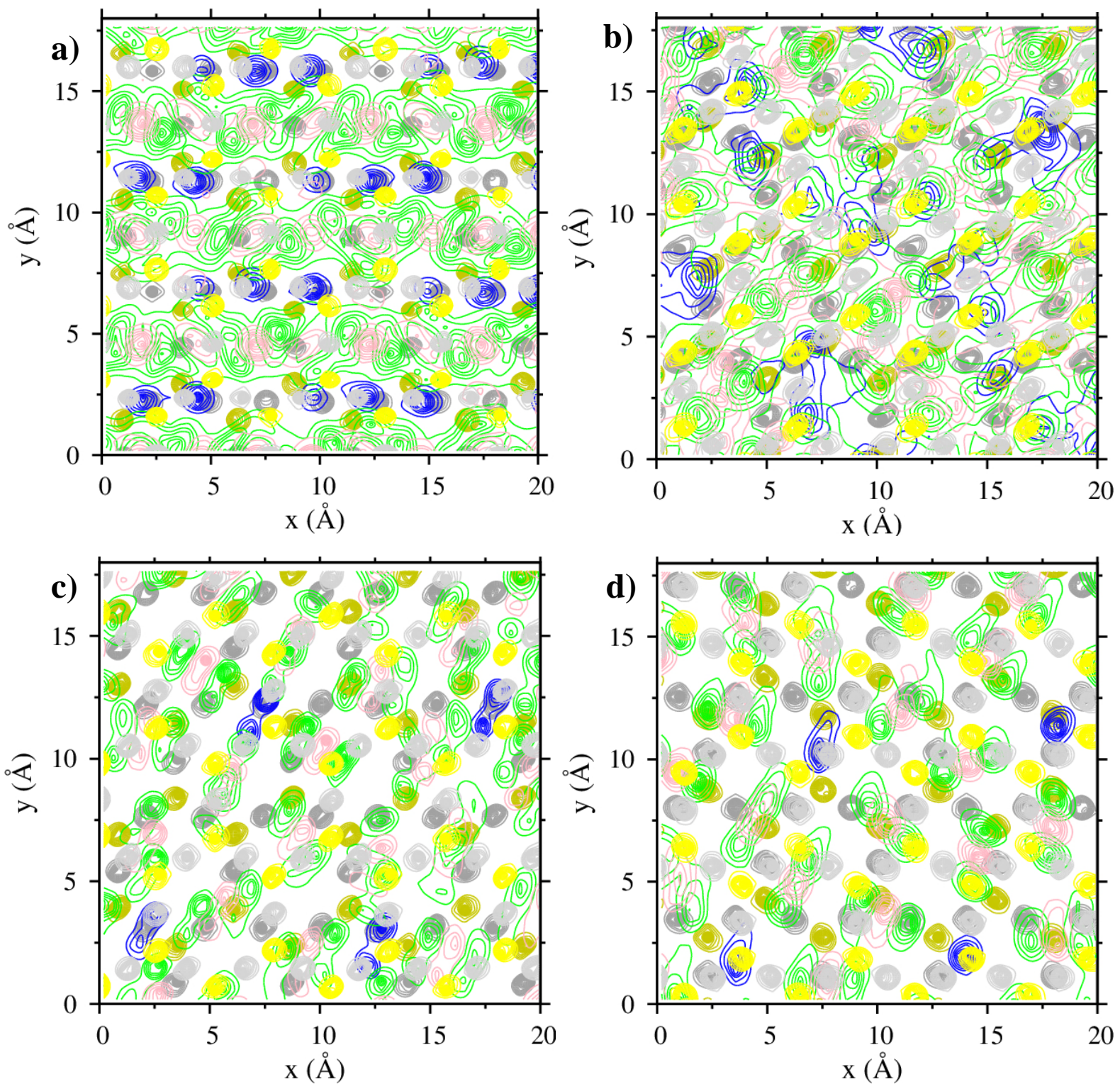

Figure 8. Computed PADDs of interlayer metal cations and intercalated $\mathrm{CO}_{2}$ molecules in hectorite interlayers at monolayer distances and $323 \mathrm{~K}$ and 90 bar. a) $\mathrm{Na}^{+}$and $\mathrm{CO}_{2}$ in Na-hectorite; b) $\mathrm{Cs}^{+}$and $\mathrm{CO}_{2}$ in Cs-hectorite; c) $\mathrm{Mg}^{2+}$ and $\mathrm{CO}_{2}$ in Mg-hectorite; d) $\mathrm{Ba}^{2+}$ and $\mathrm{CO}_{2}$ in Ba-hectorite. Color code: $\mathrm{O}_{\mathrm{b}}$ - gray (dark and light), $\mathrm{Si}-$ yellow (dark and light), Cation $\left(\mathrm{Na}^{+}, \mathrm{Cs}^{+}, \mathrm{Mg}^{2+}, \mathrm{Ba}^{2+}\right)-$ blue, $\mathrm{O}_{\mathrm{CO} 2}-$ green, $\mathrm{C}_{\mathrm{CO} 2}-$ pink, Dark colors correspond to the $\mathrm{O}_{\mathrm{b}}$ and $\mathrm{Si}$ of one hectorite basal surface, and light colors correspond to those atoms of the opposite basal surface. 


\section{References}

1. Gauss, I. Role and Impact of $\mathrm{CO}_{2}$-Rock Interactions during $\mathrm{CO}_{2}$ Storage in Sedimentary Rocks. Int. J. Green. Gas Cont. 2010, 4, 73-89.

2. Lackner, K. S. A Guide to $\mathrm{CO}_{2}$ Sequestration. Science 2003, 300, 1677-1678.

3. Benson, S. M.; Cole, D. R. $\mathrm{CO}_{2}$ Sequestration in Deep Sedimentary Formations. Elements 2008, 4, 325-331.

4. Bachu, S.; Bonijoly, D.; Bradshaw, J.; Burruss, R.; Holloway, S.; Christensen, N. P.; Mathiassen, O. M. $\mathrm{CO}_{2}$ Storage Capacity Estimation: Methodology and Gaps. Int. J. Green. Gas Cont. 2007, 1, 430-443.

5. Wilkin, R. T.; Digiulio, D. Geochemical Impacts to Groundwater from Geologic Carbon Sequestration: Controls on $\mathrm{pH}$ and Inorganic Carbon Concentrations from Reaction Path and Kinetic Modeling. Environ. Sci. Technol. 2010, 44, 4821-4827.

6. Berrezueta, E.; Menendez, G-, L.; Breitner, D.; Luquot, L. Pore System Changes During Experimental $\mathrm{CO}_{2}$ Injection into Detritic Rocks. Studies of Potential Storage Rocks from Some Sedimentary Basins of Spain. Int. J. Green. Gas Cont. 2013, 4, 73-89

7. Meakin, P.; Tartakovsky, A. M. Modeling and Simulation of Pore-Scale Multiphase Fluid Flow and Reactive Transport in Fractured and Porous Media. Rev. Geophys. 2009, 47, RG3002.

8. Davis, A. J.; Kent, B. D. Surface Complexation Modeling in Aqueous Geochemistry. Rev. Mineral. 1990, 23, 177-260.

9. $\quad$ Bowers, G. M.; Schaef, H. T.; Loring, J. S.; Hoyt, D. W.; Burton, S. D.; Walter, E. D.; Kirkpatrick, R. J. Role of Cations in $\mathrm{CO}_{2}$ Adsorption, Dynamics and Hydration in Smectite Clays under In Situ Supercritical $\mathrm{CO}_{2}$ Conditions. J. Phys. Chem. C 2017, 121, 577-592.

10. Wang, Z.; Felmy, A. R.; Thompson, C. J.; Loring, J. S.; Joly, A. G.; Rosso, K. M.; Schaef, H. T.; Dixon, D. A. Near-Infrared Spectroscopic Investigation of Water in Supercritical $\mathrm{CO}_{2}$ and the effect of $\mathrm{CaCl}_{2}$. Fluid Phase Equil. 2013, 338, 155-163.

11. Giesting, P.; Guggenheim, S.; van Groos, A. F. K.; Busch, A. Interaction of Carbon Dioxide with Na-Exchanged Montmorillonite at Pressures to 640 bar: Implications for $\mathrm{CO}_{2}$ Sequestration. Int. J. Green. Gas Cont. 2012, 8, 73-81.

12. Giesting, P.; Guggenheim, S.; van Groos, A. F. K.; Busch, A. X-ray Diffraction Study of $\mathrm{K}-$ and Ca-Exchanged Montmorillonites in $\mathrm{CO}_{2}$ Atmospheres. Environ. Sci. Technol. 2012, 46, 5623-5630.

13. Lee, M.-S.; McGrail, B. P.; Glezakou, V.-A. Microstructural Response of Variably Hydrated Ca-rich Montmorillonite to Supercritical $\mathrm{CO}_{2}$. Environ. Sci. Technol. 2014, 48, 8612-8619.

14. Ilton, E. S.; Schaef, H. T.; Qafoku, O.; Rosso, K. M.; Felmy, A. R. In Situ X-ray Diffraction Study of $\mathrm{Na}^{+}$Saturated Montmorillonite Exposed to Variably Wet Supercritical $\mathrm{CO}_{2}$. Environ. Sci. Technol. 2012, 46, 4241-4248.

15. Guggenheim, S.; van Groos, A. F. K. An Integrated Experimental System for Solid-GasLiquid Environmental Cells. Clays Clay Miner. 2014, 62, 470-476. 
16. Rother, G.; Ilton, E. S.; Wallacher, D.; Hauss, T.; Schaef, H. T.; Qafoku, O.; Rosso, K. M.; Felmy, A. R.; Krukowski, E. G.; Stack, A. G. et al. $\mathrm{CO}_{2}$ Sorption to Subsingle Hydration Layer Montmorillonite Clay Studies by Excess Sorption and Neutron Diffraction Measurements. Environ. Sci. Technol. 2013, 47, 205-211.

17. Schaef, H. T.; Ilton, E. S.; Qafoku, O.; Martin, P. F.; Felmy, A. R.; Rosso, K. M. In Situ $\mathrm{X}-\mathrm{RD}$ study of $\mathrm{Ca}^{2+}$ Saturated Montmorillonite (STx-1) Exposed to Anhydrous and Wet Supercritical Carbon Dioxide. Int. J. Green. Gas Cont. 2012, 6, 220-229.

18. Romanov, V. N. Evidence of Irreversible $\mathrm{CO}_{2}$ Intercalation in Montmorillonite. Int. J. Green. Gas Cont. 2013, 14, 220-226.

19. Schaef, H. T.; Loring, J. S.; Glezakou, V. A.; Miller, Q. R. S.; Chen, J.; Owen, A. T.; Lee, M.-S.; Ilton, E. S.; Felmy, A. R.; McGrail, B. P. et al. Competitive Sorption of $\mathrm{CO}_{2}$ and $\mathrm{H}_{2} \mathrm{O}$ in 2:1 Layer Phyllosilicates. Geochim. Cosmochim. Acta 2015, 161, 248-257.

20. Loring, J. S.; Schaef, H. T.; Turcu, R. V. F.; Thompson, C. J.; Miller, Q. R.; Martin, P. F.; Hu, J.; Hoyt, D. W.; Qafoku, O.; Ilton, E. S. et al. In Situ Molecular Spectroscopic Evidence for $\mathrm{CO}_{2}$ Intercalation into Montmorillonite in Supercritical Carbon Dioxide. Langmuir 2012, 28, 7125-7128.

21. Loring, J.S.; Ilton, E.S.; Chen, J.; Thompson, C.J.; Martin, P.F.; Benezeth, P.; Rosso, K.M.; Felmy, A.R.; Schaef, H.T. In Situ Study of $\mathrm{CO}_{2}$ and $\mathrm{H}_{2} \mathrm{O}$ Partitioning Between NaMontmorillonite and Variably Wet Supercritical Carbon Dioxide. Langmuir 2014, 30, 6120-6128.

22. Loring, J. S.; Schaef, H. T.; Thompson, C. J.; Turcu, R. V. F.; Miller, Q. R.; Chen, J.; Hu, J.; Hoyt, D. W.; Martin, P. F.; Ilton, E. S. et al. Clay Hydration/Dehydration in Dry to Water-Saturated Supercritical $\mathrm{CO}_{2}$ : Implications for Caprock Integrity. Energy Procedia 2013, 37, 5443-5448.

23. Krukowski, E.G.; Goodman, A.; Rother, G.; Ilton, E.S.; Guthrie, G.; Bodnar, R.J. FT-IR Study of $\mathrm{CO}_{2}$ Interaction with $\mathrm{Na}^{+}$Exchanged Montmorillonite. Appl. Clay Sci. 2015, 114, 61-68.

24. Bowers, G. M.; Hoyt, D. W.; Burton, S. D.; Ferguson, B. O.; Varga, R.; Kirkpatrick, R. J. In Situ ${ }^{13} \mathrm{C}$ and ${ }^{23} \mathrm{Na}$ Magic Angle Spinning NMR Investigation of Supercritical $\mathrm{CO}_{2}$ Incorporation in Smectite-Natural Organic Matter Composites. J. Phys. Chem. C 2014, 118, 3564-3573.

25. Bowers, G. M.; Bish, D. L.; Kirkpatrick, R. J. Cation Exchange at the Mineral-Water Interface: $\mathrm{H}_{3} \mathrm{O}^{+} / \mathrm{K}^{+}$Competition at the Surface of Nano-Muscovite. Langmuir 2008, 24 , 10240-10244.

26. Bowers, G. M.; Singer, J. W.; Bish, D. L.; Kirkpatrick, R. J. Alkali Metal and $\mathrm{H}_{2} \mathrm{O}$ Dynamics at the Clay/Water Interface. J. Phys. Chem. C 2011, 115, 23395-23407.

27. Marry, V.; Dubois, E.; Malikova, N.; Durand-Vidal, S.; Longeville, S.; Breu, J. Water Dynamics in Hectorite Clays: Influence of Temperature Studied by Coupling Neutron Spin Echo and Molecular Dynamics. Environ. Sci. Technol. 2011, 45, 2850-2855.

28. Weiss, C. A.; Kirkpatrick, R. J.; Altaner, S. P. Variations in Interlayer Cation Sites of Clay Minerals as Studied by ${ }^{133}$ Cs MAS Nuclear Magnetic Resonance Spectroscopy. Amer. Mineral. 1990, 75, 970-982. 
29. Weiss, C. A.; Kirkpatrick, R. J.; Altaner, S. P. The Structural Environments of Cations Adsobed onto Clays - ${ }^{133}$ Cs Variable-Temperature MAS NMR Spectroscopic Study of Hectorite. Geochim. Cosmochim. Acta 1990, 54, 1655-1669.

30. Morrow, C. P.; Yazaydin, A. O.; Krishnan, M.; Bowers, G. M.; Kalinichev, A. G.; Kirkpatrick. R. J. Structure, Energetics and Dynamics of Smectite Clay Interlayer Hydration: Molecular Dynamics and Metadynamics Investigation of Na-Hectorite. $J$. Phys. Chem. C 2013, 117, 5172-5187.

31. Reddy, U. V.; Bowers, G. M.; Loganathan, N.; Bowden, M.; Yazaydin, A. O.; Kirkpatrick, R. J. Water Structure and Dynamics in Smectites: ${ }^{2} \mathrm{H}$ NMR Spectroscopy of Mg, Ca, Sr, Cs and Pb-Hectorite. J. Phys. Chem. C 2016, 120, 8863-8876.

32. Marry, V.; Malikova, N.; Cadene, A.; Dubois, E.; Durand-Vidal, S.; Turq, P.; Breu, J.; Longeville, S.; Zanotti, J. M. Water Diffusion in a Synthetic Hectorite by Neutron Scattering - Beyond the Isotropic Translational Model. J. Phys.: Cond. Matter 2008, 20, 104205.

33. Loganathan, N.; Yazaydin, A. O.; Bowers, G. M.; Kalinichev, A. G.; Kirkpatrick, R. J. Structure, Energetics and Dynamics of $\mathrm{Cs}^{+}$and $\mathrm{H}_{2} \mathrm{O}$ in Hectorite: Molecular Dynamics Simulations with Unconstrained Substrate Surface. J. Phys. Chem. C 2016, 120, 1029810310.

34. Porion, P.; Faugere, A. M.; Delville, A. Multiscale Water Dynamics within Dense Clay Sediments Probed by ${ }^{2} \mathrm{H}$ Multiquantum NMR Relaxometry and Two-Time Stimulated Echo NMR Spectroscopy. J. Phys. Chem. C 2013, 117, 26119-26134.

35. Loganathan, N.; Yazaydin, A. O.; Bowers, G. M.; Kalinichev, A. G.; Kirkpatrick, R. J. Cation and Water Structure, Dynamics and Energetics in Smectite Clays: A Molecular Dynamics Study of Ca-Hectorite J. Phys. Chem. C 2016, 120, 12429-12439.

36. Greathouse, J. A.; Hart, D. B.; Bowers, G. M.; Kirkpatrick, R. J.; Cygan, R. T. Molecular Simulation of Structure and Diffusion at Smectite-Water Interfaces: Using Expanded Clay Interlayers as Model Nanopores. J. Phys. Chem. C 2015, 119, 17126-17136.

37. Ngouana-Wakou. B.F.; Kalinichev, A.G. Structural Arrangements of Isomorphic Substitutions in Smectites: Molecular Simulation of the Swelling Properties, Interlayer Structure and Dynamics of Hydrated Cs-Montmorillonite Revisited with New Clay Models. J. Phys. Chem. C 2014, 118, 12758-12773.

38. Sato, T.; Watanabe, T.; Otuka, R. Effects of Layer Charge, Charge Location, and Energy Change on Expansion Properties of Dioctahedral Smectites. Clays Clay Miner. 1992, 29, 873-882.

39. Wang, J.; Kalinichev, A.G.; Kirkpatrick, R.J. Effects of Substrate Structure and Composition on the Structure, Dynamics and Energetics of Water at Mineral Surfaces: A Molecular Dynamics Modeling Study. Geochim. Cosmochim. Acta 2006, 70, 562-582.

40. Botan, A.; Rotenberg, R.; Marry, V.; Turq, P.; Noetinger, B. Carbon Dioxide in Montmorillonite Clay Hydrates: Thermodynamics, Structure and Transport from Molecular Simulation. J. Phys. Chem. C 2010, 114, 14962-14969.

41. Kadoura, A.; Nair, A. K. N.; Sun, S. Molecular Simulation Study of Montmorillonite in Contact with Variably Wet Supercritical Carbon Dioxide. J. Phys. Chem. C 2017, 121, 6199-6208. 
42. Myshakin, E. M.; Saidi, W. A.; Romanov, V. N.; Cygan, R. T.; Jordan, K. D. Molecular Dynamics Simulations of Carbon Dioxide Intercalation in Hydrated Na-Montmorillonite. J. Phys. Chem. C 2013, 117, 11028-11039.

43. Makaremi, M.; Jordan, K. D.; Guthrie, G. D.; Myshakin, E. M. Multiphase Monte Carlo and Molecular Dynamics Simulations of Water and $\mathrm{CO}_{2}$ Intercalation in Montmorillonite and Beidellite. J. Phys. Chem. C 2015, 119, 15112-15124.

44. Rao, A.; Leng, Y., Molecular Understanding of $\mathrm{CO}_{2}$ and $\mathrm{H}_{2} \mathrm{O}$ in a Montmorillonite Clay Interlayer Under $\mathrm{CO}_{2}$ Geological Sequestration Conditions. J. Phys. Chem. C 2016, 120, 2642-2654.

45. Rao, A.; Leng, Y. Effect of Layer Charge on $\mathrm{CO}_{2}$ and $\mathrm{H}_{2} \mathrm{O}$ Intercalations in Swelling Clays. Langmuir 2016, 32, 11366-11374.

46. Sena, M. M.; Morrow, C. P.; Kirkpatrick, R. J.; Krishnan, M. Structure, Energetics, and Dynamics of Supercritical Carbon Dioxide at Smectite Mineral-Water Interfaces: Molecular Dynamics Modeling and Adaptive Force Investigation of $\mathrm{CO}_{2} / \mathrm{H}_{2} \mathrm{O}$ Mixtures Confined in Na-Montmorillonite. Chem. Mater. 2015, 27, 6946-6959.

47. Yazaydin, A. O.; Bowers, G. M.; Kirkpatrick, R. J. Molecular Dynamics Modeling of Carbon Dioxide, Water and Natural Organic Matter in Na-Hectorite. Phys. Chem. Chem. Phys. 2015, 17, 23356-23367.

48. Loganathan, N.; Yazaydin, A. O.; Bowers, G. M.; Kalinichev, A. G.; Kirkpatrick, R. J. Molecular Dynamics Study of $\mathrm{CO}_{2}$ and $\mathrm{H}_{2} \mathrm{O}$ Intercalation in Smectite Clays: Effect of Temperature and Pressure on Interlayer Structure and Dynamics in Hectorite J. Phys. Chem. C 2017, 121, 24527-24540.

49. Luquot, L.; Gouze, P. Experimental Determination of Porosity and Permeability Changes Induced Injection of $\mathrm{CO}_{2}$ into Carbonate Rocks. Chem. Geol. 2009, 265, 148-159.

50. Vickerd, M. A.; Thring, R. W.; Arocena, J. M.; Li, J. B. Changes in Porosity due to Acid Gas Injection as Determined by X-ray Computed Tomography. J. Can. Petrol. Techn. 2006, 45(8), 17-22.

51. Schaef, H. T.; Loganathan, N.; Bowers, G. M.; Kirkpatrick, R.; Yazaydin, A. O.; Burton, S. D.; Hoyt, D. W.; Ilton, E. S.; Thanthiriwatte, K. S.; Dixon, D. A. et al. Tipping Point for Expansion of Layered Aluminosilicates in Weakly Polar Solvents: Supercritical $\mathrm{CO}_{2}$. Appl. Mater. Interf. 2017, 9, 36783-36791.

52. Bowers, G. M.; Singer, J. W.; Bish, D. L.; Kirkpatrick, R. J. Structure and Dynamical Relationships of $\mathrm{Ca}^{2+}$ and $\mathrm{H}_{2} \mathrm{O}$ in Smectite/ ${ }^{2} \mathrm{H}_{2} \mathrm{O}$ Systems. Amer. Mineral. 2014, 99, 318331.

53. Hoyt, D. W.; Turcu, R. V. F.; Sears, J. A.; Rosso, K. M.; Burton, S. D.; Felmy, A.; Hu, J. Z. High-Pressure Magic Angle Spinning Nuclear Magnetic Resonance. J. Magn. Reson. 2011, 212, 378-385.

54. Turcu, R. V. F.; Hoyt, D. W.; Rosso, K. M.; Sears, J. A.; Loring, J. S.; Felmy, A.; Hu, J. Z. Rotor Design for High Pressure Magic Angle Spinning Nuclear Magnetic Resonance. J. Magn. Reson. 2013, 226, 64-69.

55. Tenorio, R. P.; Alme, L. R.; Engelsberg, M.; Fossum, J. O.; Hallwass, F. Geometry and Dynamics of Intercalated Water in Na-Fluorohectorite Clay Hydrates. J. Phys. Chem. C 2008, 112, 575-580. 
56. Dazas, B.; Lanson, B.; Breu, J.; Robert, J-L.; Pelletier, M.; Ferrage, E., Smectite Fluorination and its Impact on Interlayer Water Content and Structure: A way to Fine Tune the Hydrophobicity of Clay Surfaces? Micro. Meso. Mater. 2013, 181, 233-247.

57. Lowenstein, W. The Distribution of Aluminium in the Tetrahedra of Silicates and Aluminates. Amer. Mineral. 1954, 39, 92-96.

58. Boinepalli, S.; Attard, P. Grand Canonical Molecular Dynamics. J. Chem. Phys. 2003, 119, 12769-12775.

59. Dubbeldam, D.; Calero, S.; Ellis, D. E.; Snurr, R. Q. RASPA: Molecular Simulation Software for Adsorption and Diffusion in Flexible Nanoporous Materials. Mol. Sim. 2016, 42, 81-101.

60. Young, D. A.; Smith, D. E. Simulations of Clay Mineral Swelling and Hydration: Dependence upon Interlayer Ion Size and Charge. J. Phys. Chem. B 2000, 104, 91639170.

61. Cygan, R. T.; Liang, J.-J.; Kalinichev, A. G. Molecular Models of Hydroxide, Oxyhydroxide and Clay Phases and the Development of a General Force Field. J. Phys. Chem. B 2004, 108, 1255-1266.

62. Cygan, R. T.; Romanov, V. N.; Myshakin, E. M. Molecular Simulation of Carbon Dioxide Capture by Montmorillonite Using an Accurate and Flexible Force Field. $J$. Phys. Chem. C 2012, 116, 13079-13091.

63. Allen, M. P.; Tildesley, D. J. Computer Simulations of Liquids; Clarendon Press: Oxford, U.K., 1987.

64. Peng, D. Y.; Robinson, D. B. A New Two-Constant Equation of State. Ind. Eng. Chem. Fundam. 1976, 15, 59-64.

65. Smith, D. E. Molecular Computer Simulations of the Swelling Properties and Interlayer Structure of Cesium Montmorillonite. Langmuir 1998, 14, 5959-5967.

66. Berend, I.; Cases, J. M.; Francois, M.; Uriot, J. P.; Michot, L.; Masion, A.; Thomas, F., Mechanism of Adsorption and Desorption of Water-Vapor by Homoionic Montmorillonites 2. The $\mathrm{Li}^{+}, \mathrm{Na}^{+}, \mathrm{K}^{+}, \mathrm{Rb}^{+}, \mathrm{Cs}^{+}$-Exchanged Forms. Clays Clay Miner. 1995, 43, 324-336.

67. Hemmen, H.; Rolseth, E. G.; Fonseca, D. M.; Hansen, E. L; Fossum, J. O.; Plivelic, R. $\mathrm{X}$-ray Studies of Carbon Dioxide Intercalation in Na-Fluorohectorite Clay at NearAmbient Conditions. Langmuir. 2012, 28, 1678-1682.

68. Criscenti, L. J.; Cygan, R. T., Molecular Simulations of Carbon Dioxide and Water: Cation Solvation. Environ. Sci. Technol. 2013, 47, 87-94.

69. Sutton, R.; Sposito, G. Molecular Simulation of Interlayer Structure and Dynamics in 12.4Å Cs-Smectite Hydrates. J. Coll. Interf. Sci. 2001, 237, 174-184.

70. Seidl, W.; Breu, J. Single Crystal Structure Refinement of TetramethylammoniumHectorite. Z. Kristallogr. 2005, 220, 169-176.

71. Kosakowski, G.; Churakov, S. V.; Thoenen, T. Diffusion of $\mathrm{Na}$ and $\mathrm{Cs}$ in Montmorillonite. Clays Clay Miner. 2008, 56, 190-206. 
TOC Graphic

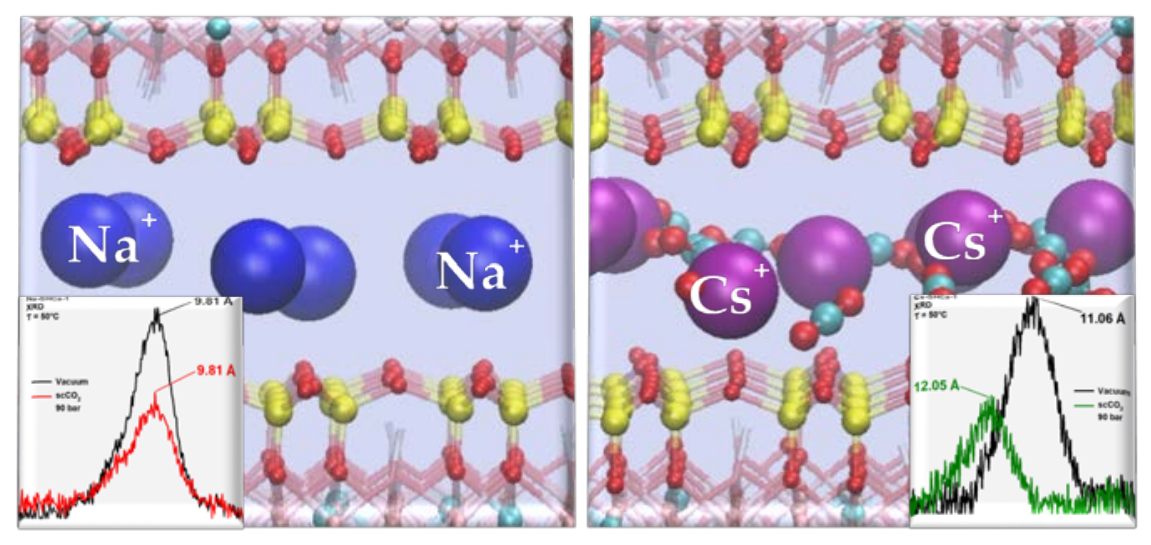

